\title{
Spatial Variation and Terrain Gradient Effect of Ecosystem Services in Heihe River Basin over the Past 20 Years
}

\author{
Lingge Zhang and Ningke $\mathrm{Hu}$ *
}

check for

updates

Citation: Zhang, L.; Hu, N. Spatial Variation and Terrain Gradient Effect of Ecosystem Services in Heihe River Basin over the Past 20 Years. Sustainability 2021, 13, 11271. https:/ / doi.org/10.3390/su132011271

Academic Editors: Kikuko Shoyama,

Rajarshi Dasgupta and Ronald

C. Estoque

Received: 1 September 2021

Accepted: 1 October 2021

Published: 13 October 2021

Publisher's Note: MDPI stays neutral with regard to jurisdictional claims in published maps and institutional affiliations.

Copyright: (C) 2021 by the authors Licensee MDPI, Basel, Switzerland. This article is an open access article distributed under the terms and conditions of the Creative Commons Attribution (CC BY) license (https:/ / creativecommons.org/licenses/by/ $4.0 /)$.
School of Geography and Tourism, Shaanxi Normal University, Xi'an 710119, China; zlg98@snnu.edu.cn

* Correspondence: hunk2014@snnu.edu.cn

\begin{abstract}
With the advent of large-scale development, extreme imbalance in the ecology of the Heihe River Basin (HRB) has caused a series of ecological problems. In order to explore the spatiotemporal variation of ecosystem services (ESs) and to assess the characteristics of ESs under the terrain gradient effect (TGE), the three key ESs were quantified based on the InVEST model using five series of land-use data obtained from remote sensing images from 2000 to 2020 in this study. The terrain index was used to analyze the influence of terrain on ESs. The results show that most of the ESs were in high numbers in the south and low numbers in the north, as well as high numbers in the middle and upper reaches and low numbers at downstream locations. It was found that high-quality habitats degrade to general-quality habitats, and poor-quality habitats evolve into general-quality habitats. It was also found that the water production volume continues to decline and soil conservation becomes relatively stable with little change. This study illustrates different ESs showing obvious TGE with changes in elevation and slope. These results indicate that the effect of land-use change is remarkable and TGE is highly important to ESs in inland watersheds. This research study can provide a scientific basis for the optimization of regional ecosystem patterns. The results are of great significance in terms of rational planning land use, constructing ecological civilizations, and maintaining the physical conditions of land cover at inland river basins.
\end{abstract}

Keywords: land use; ecosystem services; InVEST; topographic index; ecosystem pattern

\section{Introduction}

Ecosystem services (ESs), which are the benefits that humans receive directly or indirectly from ecosystems, have played an important role in the development of human civilization [1]. Generally, ESs include food supply, climate regulation, and cultural and supporting services. In recent years, the conflicts between the rapid socio-economic development and the consumption of natural resources and environmental change have resulted in the degradation of ESs and frequent natural disasters in some areas [2-4]. ESs have been considered as indispensable features in land-use planning and resource adjustment, becoming one of the research hotspots over recent decades. Currently, ES assessments mostly focus on different land-use scenarios, such as croplands, forests, oceans, lakes, wetlands, and others [5-8]. In order to ensure the sustainable provision of ESs for human beings, it is necessary to evaluate ESs in order to support human wellbeing. ES evaluations consist of a value assessment and material quality assessment [9-11]. The former measures the economic value of ESs by using ecological economics methods [12-14] that are based on the value equivalent factor of a unit area or the price of a unit service function [15-21]. The value measurement method is primarily used to evaluate supply services, and the results are of high economic significance [22-24]. With the refinement of the ES classification, material quality methods are gradually used as the mainstream assessment methods of ESs. The material quality of various ESs can be quantitatively evaluated based on ecological principles in this method. By contrast, the credibility and accuracy of the quality assessment method are higher than that of the value assessment method, which is influenced 
subjectively to some extent [25]. It is necessary to conduct research on the sustainability of an ecosystem and to provide a more scientific and reliable basis for decision making [11]. Material quality assessment methods can be roughly divided into emergy methods and model methods [26]. The emergy method is based on the emergy theory for evaluating different types of emergy and material flows in the system [27]. It combines the total amount of effective energy invested directly and indirectly in the ecosystem with the energy conversion rate to calculate the final energy value. The energy flow and utilization rate of ESs can be expressed better by emergy evaluation. This method is often used to describe the regional differences with the utilization of ESs in large-scale areas and to evaluate urban ecosystems [28]. However, with increasing studies on the coupling of multiple ESs and the relationship between ESs and human wellbeing during these years, the emergence and development of evaluation models represent a major breakthrough in the field of ES assessment. The results can be presented in the form of a map incorporating more spatial and intuitive information by using model assessments. It can simulate and predict the changing scenario of future ESs.

According to the formation mechanism of ESs, studies on ES evaluation have increased due to the quality assessments of ecosystems generated through comprehensive models. The commonly used models include Integrated Valuation Ecosystem Services and Tradeoffs (InVEST), Artificial Intelligence for Ecosystem Services (ARIES), Social Value for Ecosystem Services (SolVES), and Multi-scale Integrated Models of Ecosystem Services (MIMES) [29,30]. Some models, such as SoLVES, ARIES, and MIMES, output good evaluations for specific regions and have promising application prospects, but they have not been fully developed yet. The InVEST model is the most widely used tool for the quality assessment of ESs. The advantages of the InVEST model have been highlighted by integrating various service production functions or simulating service dynamic changes. Previous assessment studies using the InVEST model are mostly concentrated in small-scale areas, such as administrative regions, urban economic zones, or lakes and rivers [31-36]. ES evaluations in medium and large watershed scales are relatively rare. In addition, most of the studies analyzed spatiotemporal pattern changes or showed cold and hot spots in the service space by spatial mapping for individual or several services, such as biodiversity conservation, water conservation, soil conservation, and carbon storage [33-38]. Relatively few studies discuss the connection and divergence between different ES supplies and specific natural environmental factors $[39,40]$. As an important factor in the natural environment, the terrain factor is of great significance for fully understanding the spatiotemporal difference of ESs [41,42]. It is well known that ESs are closely related to their terrain $[43,44]$. Some terrain-based studies analyzed the spatial distribution of land-use patterns $[45,46]$ and some were focused on mountain areas $[47,48]$. However, there are only a few studies assessing the impact of topographic factors on the spatial heterogeneity of ESs. The evaluation of the characteristics of ESs with terrain gradients has not been explored in depth. Understanding the influence of topographic elements on the spatial difference of ESs comprehensively is of great significance for deepening the understanding of ES differentiation and for ensuring effective ecosystem management.

The Heihe River Basin (HRB) is not only a key area with respect to the ecological safety barrier, but it is also an important node in the layout of the national "Belt and Road" initiative $[49,50]$. Typical natural conditions and long-term, frequent human activities have resulted in ecological environmental deterioration in the basin, resulting in the degradation of biodiversity, water production, soil, and water conservation. Therefore, the problem of how to maintain the stability of regional ecosystems as an economy develops is an important issue for all inland river basins in arid zones. To summarize, combined with the geographical conditions and characteristics of the HRB, we discuss the relationship between ESs and land-use changes in typical arid inland river basins from a topographical perspective on the basis of previous research studies. In this paper, we selected three key ESs (i.e., habitat quality, water yield, and soil conservation) of the HRB in Northwestern China to study. Based on the proposed framework (Figure 1), our analysis focuses on 
addressing three questions at fine scales: (1) How have ESs changed over the past 20 years and where are the areas of high and low distribution of individual ESs? (2) How are different ESs affected by terrain factors with respect to inland watershed scales? (3) How can variations of ESs guide land-use management in a river basin?

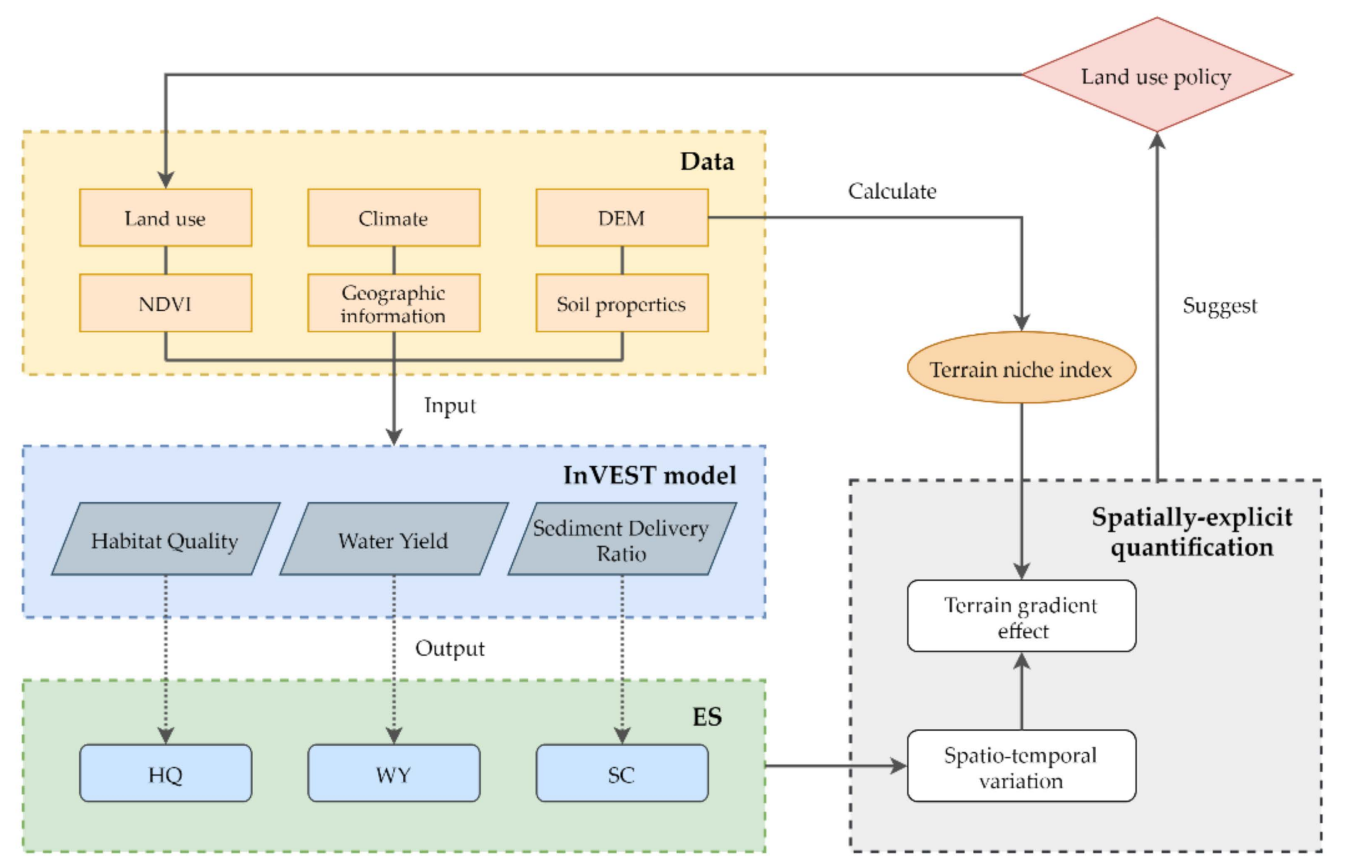

Figure 1. Framework of the methodological process in this study.

\section{Materials and Methods}

\subsection{Study Area}

The HRB is the second largest inland river basin in arid region of Northwestern China, within the range of $96^{\circ} 42^{\prime}-102^{\circ} 00^{\prime} \mathrm{E}, 34^{\circ} 41^{\prime}-42^{\circ} 42^{\prime} \mathrm{N}$ (Figure 2). The area of core drainage is approximately $128,900 \mathrm{~km}^{2}$, with a mainstream length of $821 \mathrm{~km}$. Different reaches of the river are distributed in the three provinces or autonomous region, belonging to Qinghai, Gansu, and Inner Mongolia, respectively. Climatic characteristics of the basin are a typical continental arid climate, little but concentrated precipitation, ample sunshine, and greater diurnal temperature range. With an average altitude over $1200 \mathrm{~m}$, the topography varies significantly from south to north [51]. The regional climate is significantly different in the basin. Therefore, it is an important for ecological function in terms of water production, soil conservation, biodiversity protection, windbreak, and sand fixation in Northwestern China [52].

This basin can be divided into three parts according to the locations of the gorge stations. The upstream region is located in the Qilian Mountain, with low population density, high vegetation coverage, and good ecological environment. This segment, the main contributing area, is bounded by the Yingluo Gorge. The midstream area is a main field for developing human activities, extending from the Yingluo Gorge to the Zhengyi Gorge. This region is rich in light and heat resources. The downstream region, below the Zhengyi Gorge, constitutes areas where runoff disappears. It is mostly made up of desert and bare land [53]. More than two thousand years of different human activities in HRB have caused collision and exchange of various cultures, making natural and human processes meet together. This is an ideal region for studying the variation of different ESs. 


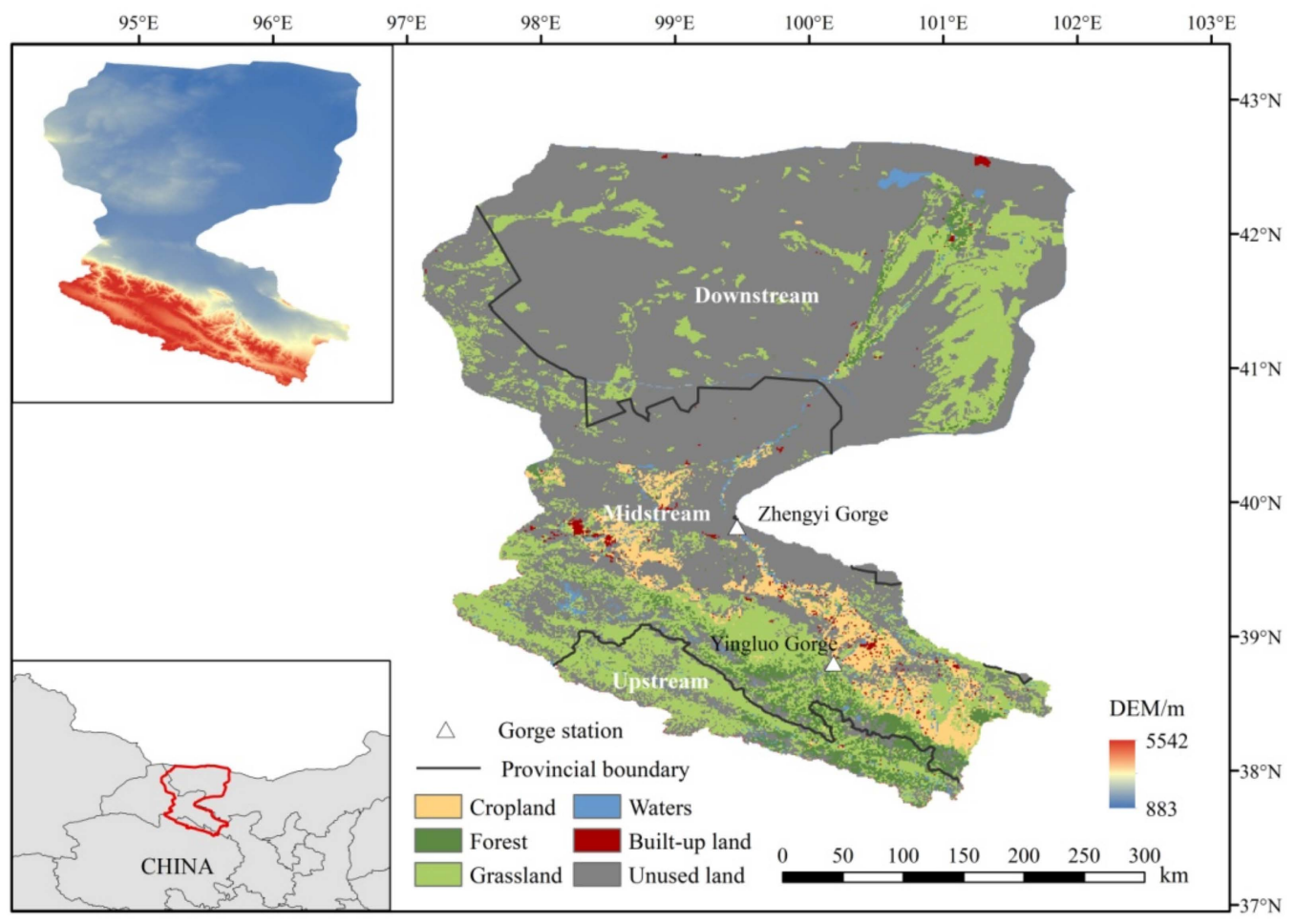

Figure 2. Location of Heihe River Basin and land use and land cover in 2015.

\subsection{Data Sources}

The datasets used in this study included: (1) land-use types in 2000, 2005, 2010, 2015 and 2020 (with a spatial resolution of $1 \mathrm{~km}$ ) and NDVI (Normalized Difference Vegetation Index). These were both obtained from the Resource and Environment Science and Data Center (http:/ / www.resdc.cn accessed on 21 March 2021). According to the model input acquirements and the reference of land-use classification system of the Resources and Environment Database, the land-use data were reclassified into six categories: cropland, forest, grassland, waters, built-up land, and unused land; (2) DEM (Digital Elevation Model) and potential evapotranspiration data (with a spatial resolution of $250 \mathrm{~m}$ ) were derived from the National Tibetan Plateau/Third Pole Environment Data Center (https:/ / data.tpdc.ac. cn/zh-hans/accessed on 24 March 2021); (3) basic geographic information data (including regional boundaries, roads, settlements, etc.) were acquired from the "Digital Heihe River" project of the Cold and Arid Region Scientific Data Center; (4) soil attribute data were derived from Chinese soil datasets (1995) in the Food and Agriculture Organization's Harmonized World Soil Database; and (5) meteorological data were retrieved from the China Meteorological Data Service Center (http:/ / www.nmic.cn/ accessed on 26 March 2021) and the National Earth System Science Data Center (http:/ / www.geodata.cn accessed on 06 April 2021), including annual, monthly, and daily value data from 2000 to 2020.

\subsection{Methodology}

In this study, terrain analysis and integrated maps were carried out by using the ArcGIS (Ver.10.2) software. Regression analyses to detect trend significance were performed in SPSS (Ver. 21.0), and visualized charts were generated by using Microsoft Excel (Ver. 2017). All the spatial assessments of ESs were processed by using InVEST (Ver. 3.8.0). As a strong technical support in ES research, the InVEST model is used for a quantitative assessment of ESs on the basis of ecosystem processes, and a full demonstration of their spatially distributed characteristics $[54,55]$. The three sub-models, habitat quality, water yield, sediment delivery and retention were selected to quantitatively evaluate and analyze 
the changes of three ESs (including habitat quality, water production and soil conservation) in this work.

\subsubsection{Habitat Quality (HQ)}

The HQ in this model can be described as the connection between different types of land use and threat sources. The results and scarcity of HQ can be obtained in accordance with the response degree of different habitats to various threat sources.

The formula for calculating habitat quality $\left(H Q_{i j}\right)$ is:

$$
H Q_{i j}=H_{j}\left(1-\frac{D_{x j}^{2}}{D_{x j}^{2}+k^{2}}\right)
$$

where $H_{j}$ is the habitat suitability of land-use type $j ; D_{x j}$ is the total threat level; $k$ is the half-saturation value.

The input data of this sub-module include current land-use and threat data. ArcGIS was used to process the original data (i.e., mosaic, reclassify, merge, etc.) in order to obtain the land-use and threat factor layer data. The HQ correlation function in the model corresponds to the four variables: the relative impact of each threat, the relative sensitivity of each habitat to each threat, the distance between habitat and threat and impact from the threat, and the level at which a grid cell of the habitat is legally protected. In order to reduce the interference of human factor on results, the impacts of the first three variables were discussed in this study. We selected cropland, town, residential area, and road as habitat threats. The corresponding parameters of the model (Tables 1 and 2) were set by referring to the user guide and previous works with similar eco-environments in arid region $[56,57]$, as well as the suggestions from experts and professors in the ecological field. The half-saturation constant defaults to 0.5 according to the user guide.

Table 1. Threat factor properties.

\begin{tabular}{ccc}
\hline Threat & Max-Dist/km & Weight \\
\hline Cropland & 1 & 0.2 \\
Town & 8 & 0.9 \\
Residential area & 3 & 0.8 \\
Road & 10 & 0.6 \\
\hline
\end{tabular}

Table 2. Sensitivity of habitat types to each threat.

\begin{tabular}{cccccc}
\hline Habitat Type & $\begin{array}{c}\text { Habitat } \\
\text { Suitability }\end{array}$ & Cropland & Town & $\begin{array}{c}\text { Residential } \\
\text { Area }\end{array}$ & Road \\
\hline Cropland & 0.4 & 0.5 & 0.4 & 0.5 & 0.45 \\
Forest & 0.8 & 0.4 & 0.8 & 0.6 & 0.5 \\
Grassland & 0.6 & 0.4 & 0.5 & 0.6 & 0.6 \\
Waters & 0.9 & 0.5 & 0.6 & 0.6 & 0.55 \\
Built-up land & 0 & 0 & 0 & 0 & 0 \\
Unused land & 0 & 0 & 0 & 0 & 0 \\
\hline
\end{tabular}

\subsubsection{Water Yield (WY)}

The WY estimation is based on the principle of water balance, which simplifies the flow process. It does not distinguish between surface runoff, runoff in the soil, and base flow. WY defines the amount of water produced within each grid range by the difference between precipitation and evapotranspiration (including plant transpiration and surface evaporation). Its calculation is based on the acquired data, such as topography, land use, meteorological factors, etc. 
The water yield $\left(W Y_{x j}\right)$ is calculated using the following formulas:

$$
\begin{gathered}
W Y_{x j}=\left(1-\frac{A E T_{x j}}{P_{x}}\right) \times P_{x} \\
\frac{A E T_{x j}}{P_{x}}=\frac{1+\omega_{x} R_{x j}}{1+\omega_{x} R_{x j}+\frac{1}{R_{x j}}} \\
\omega_{x}=Z \frac{A W C_{x}}{P_{x}} \\
R_{x j}=\frac{K_{x j} E T_{0_{x}}}{P_{x}}
\end{gathered}
$$

where $A E T_{x j}$ is the annual actual evapotranspiration for land-use type in category $j$ on grid $x(\mathrm{~mm}) ; P_{x}$ is the average annual value of precipitation on grid $x(\mathrm{~mm}) ; \omega_{x}$ is the ratio of the year's available water for modified vegetation to the expected amount of water; $R_{x j}$ is the ratio of potential evaporation to rainfall; $Z$ is the $Z$ hang coefficient, which represents the parameters of seasonal rainfall distribution and precipitation depth, ranging from 1 to 30; $A W C_{x}$ is the average annual value of available water capacity on grid $x(\mathrm{~mm}) ; E T_{0_{x}}$ is the potential evapotranspiration on grid $x(m m) ; K_{x j}$ is the evapotranspiration coefficient of vegetation. The input data of the model include precipitation, reference evapotranspiration, depth to root restricting layer, plant available water fraction, land use, and watersheds. The parameters include $\mathrm{Z}$ parameter and evapotranspiration coefficient of vegetation. The precipitation data were interpolated by using ArcGIS. The reference evapotranspiration was calculated by the modified formula. The soil depth data were derived by rasterizing the soil spatial attribute data. The plant available water fraction was set according to the reference results [58]. The watershed boundary was extracted by hydrological analysis with DEM in ArcGIS. The Zhang coefficient was set as 2.2 referring to the instruction manual and previous reference [59]. The plant evapotranspiration coefficient was defined according to the calculation method proposed by FAO and the reference value was given by the model.

\subsubsection{Soil Conservation (SC)}

The SC can be calculated with soil erosion reduction and sediment retention using the sediment delivery and retention sub-module. The decrease in soil erosion was expressed by the difference between potential erosion and actual erosion. The amount of sediment retention refers to the amount of uphill sand retained by plot. On the basis of cell scale USLE (Universal Soil Loss Equation) calculation method, the calculation on the grid unit scale was simulated using the following data, including land-use data, soil attribute, DEM, rainfall data, vegetation cover factor, and soil and water protection measure factor. The rainfall erosivity was calculated using observation data from meteorological stations in the basin and then interpolated with Kriging method in ArcGIS. The soil erodibility factor was calculated from the soil attribute data by formula-10. The vegetation cover factor and soil and water protection measure factor can be defined by consulting the user guide.

The formulas for calculating SC are defined as the following:

$$
\begin{gathered}
\text { SC }=U S L E-R K L S+S E D R \\
U S L E=R \times K \times L S \times C \times P \\
R K L S=R \times K \times L S \\
R=\sum_{i=1}^{12}\left[1.735 \times 10^{\left(1.5 \lg \frac{P_{i}^{2}}{P_{y}}-0.8188\right)}\right] \times 17.02
\end{gathered}
$$




$$
\begin{gathered}
K=0.1317 \times\{0.2+ \\
\left.\quad 0.3 \times \exp \left[-0.0265 S A N\left(1-\frac{S I L}{100}\right)\right]\right\} \times\left[\frac{S I L}{C L A+S I L}\right]^{0.3} \\
\quad \times\left\{1-0.25 \times \frac{C_{0}}{C_{0}+\exp \left(3.72-2.95 C_{0}\right)}\right\} \\
\quad \times\left\{1-0.7 \times \frac{S N_{1}}{S N_{1}+\exp \left(22.9 S N_{1}-5.51\right)}\right\} \\
\quad S N_{1}=1-\frac{S A N}{100} \\
c=\frac{N D V I-N D V I_{\text {min }}}{N D V I_{\text {max }}-N D V I_{\text {min }}} \\
\left\{\begin{array}{lr}
C=1 & c=0 \\
C=0.6508-0.3436 \log c & c<78.3 \% \\
C=0 & c>78.3 \%
\end{array}\right.
\end{gathered}
$$

where $S C$ is the amount of soil conservation $\left(t \cdot h m^{-2} \cdot a^{-1}\right)$; USLE is the amount of potential soil loss in the original land-use cover $\left(t \cdot h \mathrm{~m}^{-2} \cdot a^{-1}\right)$; RKLS is the amount of potential soil loss for bare soil $\left(t \cdot \mathrm{hm}^{-2} \cdot a^{-1}\right)$; SEDR is the retention from the upstream sediment $\left(t \cdot h m^{-2} \cdot a^{-1}\right) ; R$ is the rainfall erosivity $\left(M J \cdot m m \cdot h m^{-2} \cdot h^{-1} \cdot a^{-1}\right) ; K$ is the soil erodibility factor $\left(t \cdot \mathrm{hm}^{2} \cdot h \cdot \mathrm{hm}^{-2} \cdot \mathrm{MJ}^{-1} \cdot \mathrm{mm}^{-1}\right)$; LS is the slope length gradient factor; $P$ is the soil and water protection measure factor; $P_{i}$ is the average monthly rainfall $(\mathrm{mm}) ; P_{y}$ is the average annual precipitation $(\mathrm{mm}) ; S A N, S I L$ and $C L A$ are the content values of sand grains, powder grains and sticky grains (\%); $C_{0}$ indicates the organic carbon content value (\%); $c$ is the vegetation cover; $N D V I$ is the normalized difference vegetation index; $C$ is the crop management factor (value range is between 0 and 1 ). If $C$ is 0 , the vegetation cover of the land surface is good and almost not eroded; if $C$ is 1 , there is almost no vegetation cover on the surface.

\subsection{Terrain Niche Index}

Terrain is one of the important factors affecting spatial distribution and changes in land use. TGE is also manifested as the variations in ES supply that are caused by land-use changes to some extent. The terrain differences are outstanding in HRB, which has a variety of mountain, plain, basin, and hilly geomorphological types. In order to mirror the comprehensive relationship between terrain condition and ESs, the terrain niche index was selected as a geographical factor to analyze TGE between land-use patterns and terrain gradient in this study. The terrain niche index $(T)$ can be calculated using the following formula:

$$
T=\lg \left[\left(\frac{E}{\bar{E}}+1\right) \times\left(\frac{S}{\bar{S}}+1\right)\right]
$$

where $E$ and $\bar{E}$, respectively, indicate the elevation value of any point in the region and that of the areas where the point is located; $S$ and $\bar{S}$, respectively, represent the slope value of any point in the region and the average slope value of the areas where the point is located. If terrain level index of a point is low, the elevation and the slope of this point are low values; if that of a point is centered, the values are high and low. Both are high values if that of a point is large.

\section{Results}

\subsection{Spatiotemporal Variations of ESs}

\subsubsection{Spatial Distribution and Variation of $\mathrm{HQ}$}

HQ score is a comprehensive indication of the influence of each threat factor on itself and the impact of habitat on threat resistance. The higher the number is, the better the HQ is. The HQ in this study was classified as higher $(0.8-1)$, high $(0.5-0.8)$, general $(0.3-0.5)$ and poor $(0-0.3)$. Figure 3 shows the proportion of different HQ grades in the basin. More 
than half of the HRB was in poor and average HQ over the past 20 years. Higher and high HQ account for less than $30 \%$ of the total area, and the overall proportion composition is relatively stable from 2000 to 2020 . In order to further clearly explore the changes of HQ spatial distribution over time, we calculated the difference based on the HQ data and obtained the interannual changes in four five-year periods (Figure 4). Spatial differences and variations of $\mathrm{HQ}$ are obvious throughout the basin. Most of the upstream region has high- and higher-grade HQ. There have been many changes over the past two decades, especially in the two phases of 2005-2010 and 2015-2020. The area of higher-grade HQ increased and the HQ showed an upward trend. The overall ecological environment became better, which might be the benefit of a sparse population and dense vegetation in the upper mountains. A different layout was presented in the middle stream. The south-central region was dominated by general- and high-grade HQ. The area of general HQ level increased, which was due to the human reclamation of wasteland, grasslands, and forest land, and the expansion of cultivated land and construction land in the active areas. At the same time, the area of high-level HQ also reduced with the reclamation and the degradation of grassland and forest land. By incorporating the changes of four stages, it can be found that mostly the HQ in the northern part of the midstream area was at the poor level and it increased over the past 20 years, due to large distribution of unused land. Downstream areas were clearly affected by land use. The HQ was higher in most of the east, with grasslands, woodlands and waters. Obvious increases can be seen through the four periods in this region, while the central and western regions were dominated by unused land with low coverage and the HQ levels therefore dropped. There were few changes in the areas during 2000-2005 and 2010-2015, while the HQ changed significantly and mainly increased in the other two periods. With the transformation of unused land into grasslands and woodlands, as well as the increase in water area over the past 20 years, the area of high-grade $\mathrm{HQ}$ in the downstream region increased and that of poor-grade HQ decreased gradually. This indicates that the overall HQ of the downstream area improved, which may be related to the implementation of the Heihe Ecological Water-divide Project (2000).

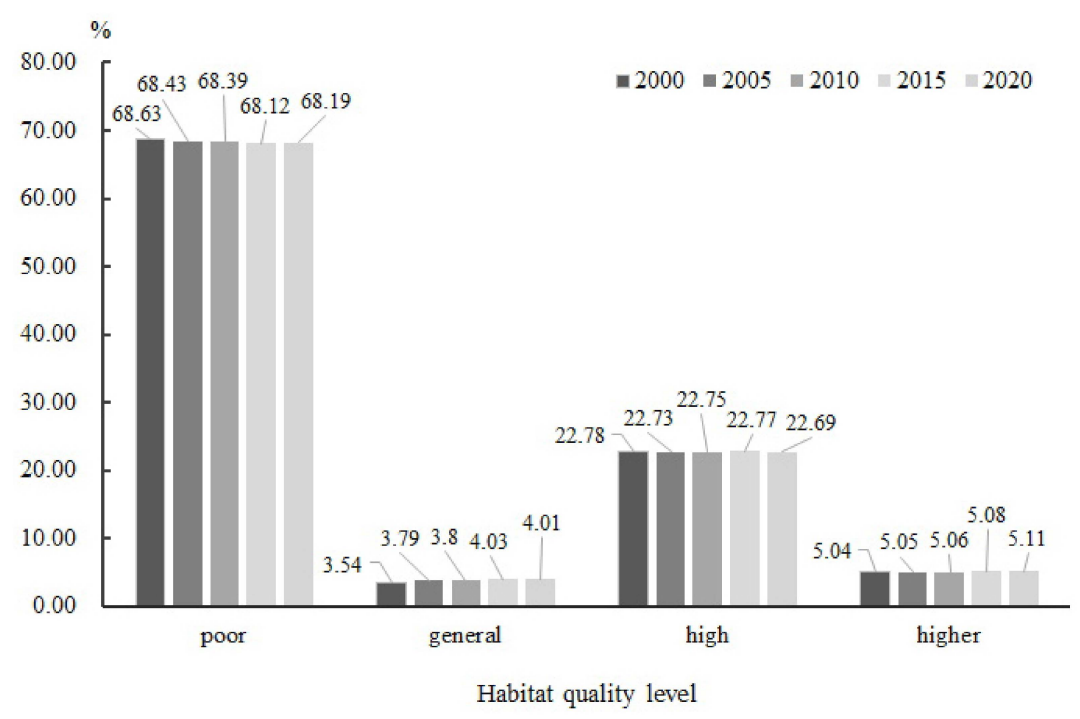

Figure 3. HQ grade ratio of different habitats in HRB from 2000 to 2020. 


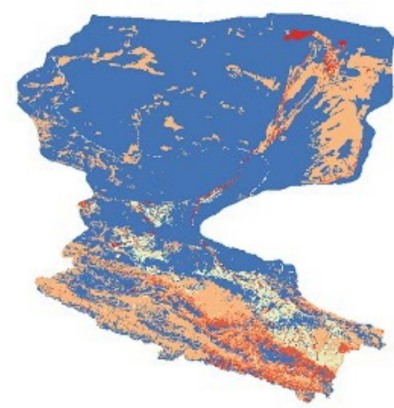

(a) 2015

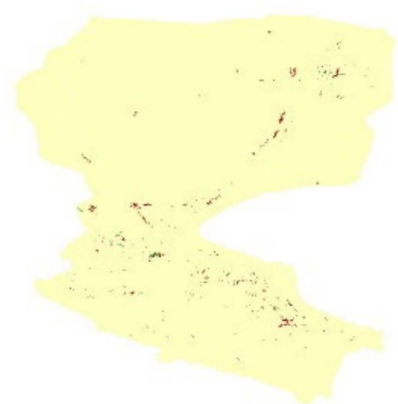

(d) 2010-2015

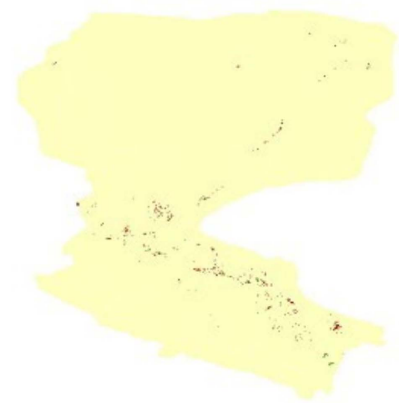

(b) 2000-2005

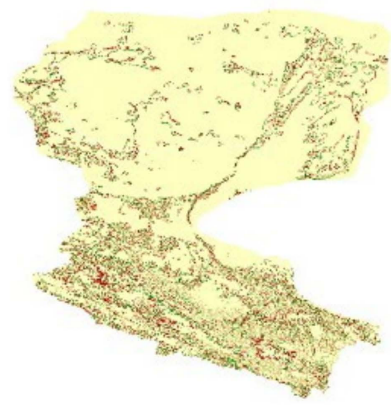

(e) 2015-2020

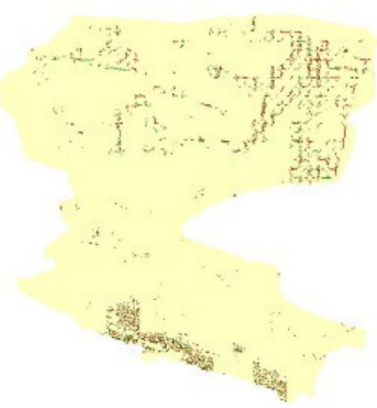

(c) 2005-2010

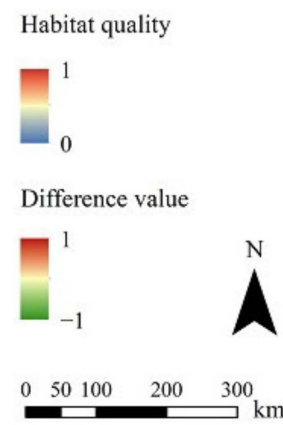

Figure 4. Variation of HQ in HRB from 2000 to 2020. (a) Spatial distribution of HQ in 2015; (b)-(e) four difference maps of the five-year changes.

Totally, the quality of habitats at all levels changed by a small margin, with a slight decrease in poor and high HQ areas and a slight increase at general and high levels. The overall HQ in the basin became better and the improvement was mostly concentrated in the upstream and downstream areas in the northeast, while the quality levels deteriorated in the midstream and lower-west regions.

\subsubsection{Spatial Distribution and Variation of WY}

The annual WY in this study was classified into one, two, three and four levels from low to higher weight (Figure 5). In 2000-2015, the proportion of low-grade WY gradually increased, while that of high-grade WY decreased bit by bit. However, during the five-year period from 2015 to 2020, the proportion of low-value WY decreased, and that of highvalue $\mathrm{WY}$ increased. However, the WY in most areas was at a lower level and the depth of water production was not large. As can be seen in Figure 6, the spatial distribution of WY shows great difference. The upstream region was the principal origin for high-value water production, and the area of high-value WY gradually decreased. In particular, some of them degraded to medium-yielding areas. However, with the exception of large-scale decline in the five years from 2010 to 2015, the changes of WY still increased in the other years. The overall trend also caused an increase in the upstream water production. The midrange showed a decreasing trend from south to north. The high-value water-producing region in the southern gradually decreased, yet some low-value water-producing areas increased to medium-yielding areas. The central and northern regions were dominated by low-value water production and continued to decrease in most areas over the past 20 years. Compared with the upper and middle reaches, the downstream area is a region with a low-value WY. Although the WY partially increased between 2005 and 2015, there has still been a slight decline in the past 20 years. The overall change was not significant. 


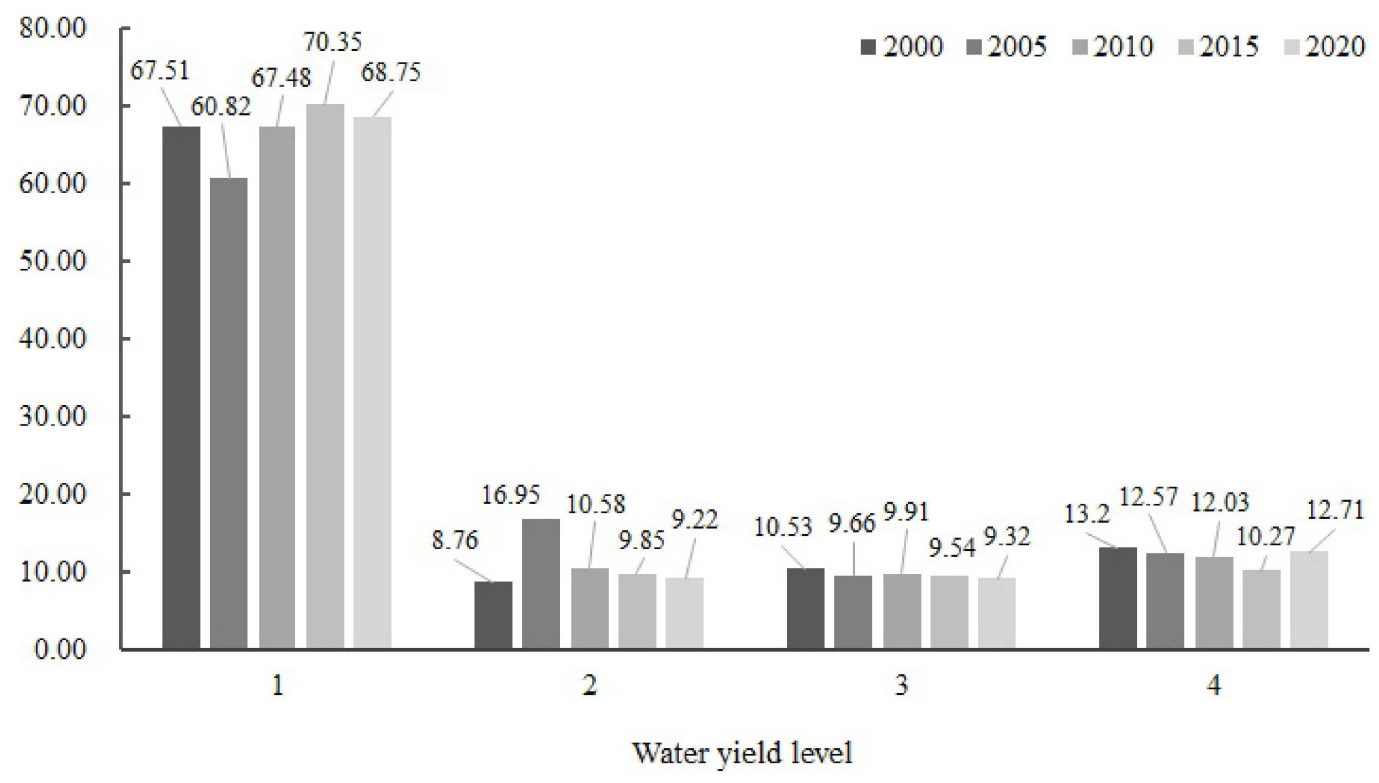

Figure 5. WY ratio of different grades in HRB from 2000 to 2020.

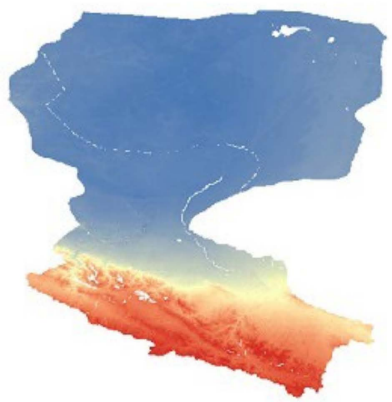

(a) 2015

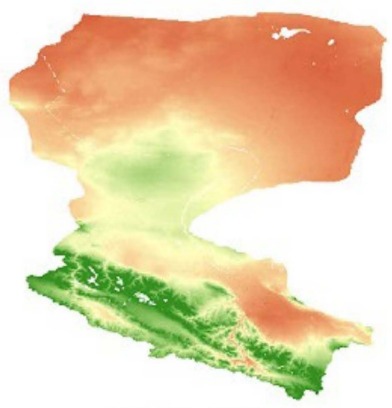

(d) 2010-2015

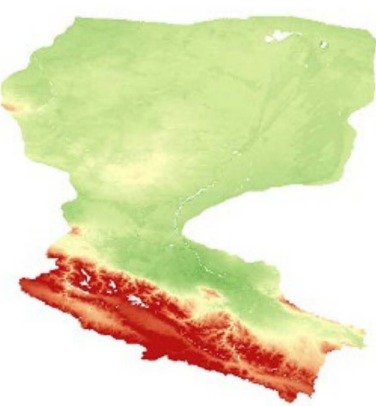

(b) 2000-2005

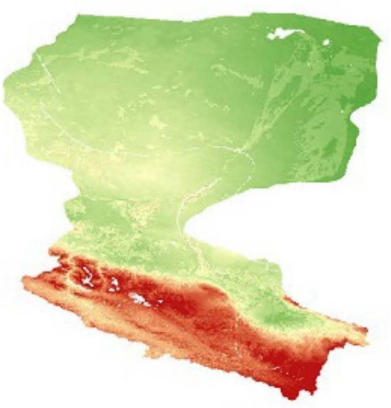

(e) 2015-2020

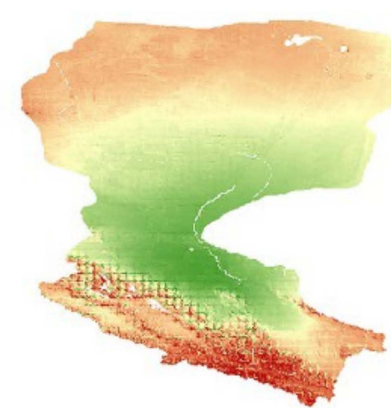

(c) 2005-2010
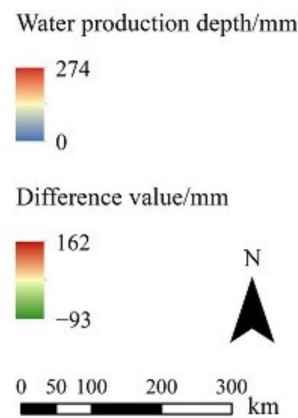

Figure 6. Variation of WY in HRB from 2000 to 2020. (a) Spatial distribution of WY in 2015; (b)-(e) four difference maps of the five-year changes.

Combined with precipitation and land use, it can be found that the spatial distribution shows consistency for WY, precipitation and vegetation in the basin. The region with strong WY capacity has high average annual precipitation and high vegetation cover and low steaming emission. On the other hand, the areas with low annual precipitation and low vegetation cover and strong steaming had a low-value WY. In terms of land-use changes from 2000 to 2020, except rainfall, the variation of WY capacity in HRB was dominated by the area decrease in grassland and forest and the area increase in unused land. Considering the effects of grassland and forest degradation through the whole basin, the overall WY finally showed continuous reduction. Compared to land use in recent years, it can be found 
that grassland provided the largest proportion among the overall WY services in the basin, reaching more than half of the total WY. This was followed by forest land and cropland.

\subsubsection{Spatial Distribution and Variation of SC}

The annual SC was classified into one, two, three and four levels, from low to higher values (Figure 7). The soil-conservation composition strongly varied through the whole basin. The low-grade SC accounts for about $70 \%$ of the total area, but there was a downward trend year by year. The proportion of SC changed little at middle and high levels. As shown in Figure 8, the spatial distribution of SC in HRB showed that high-value SC had more in the east and less in the north in the southern area. From a regional perspective, the soil holds in the upstream area was relatively small. The SC decreased in 2000-2005 and 2010-2015 and increased significantly with a wide range in the five years from 2005 to 2010. The mesh distribution of high-value SC increased over the past 20 years. The high-value SC focused on the southern part of the mid-range areas. It expanded year by year and the amount of hold increased. Conversely, soil erosion in the north region was more serious and the changes mainly occurred in the mutual transformation of low SC into medium-grade SC. As for the four stages, the changes slightly increased or decreased but were not obvious. So, the soil-keeping ability in mid-range areas has been improved since 2000. High soil holds in the downstream area were few. SC in the first decade showed an upward trend and declined in the next decade. Some soil-hold areas previously of a general level have degraded to that of low level.

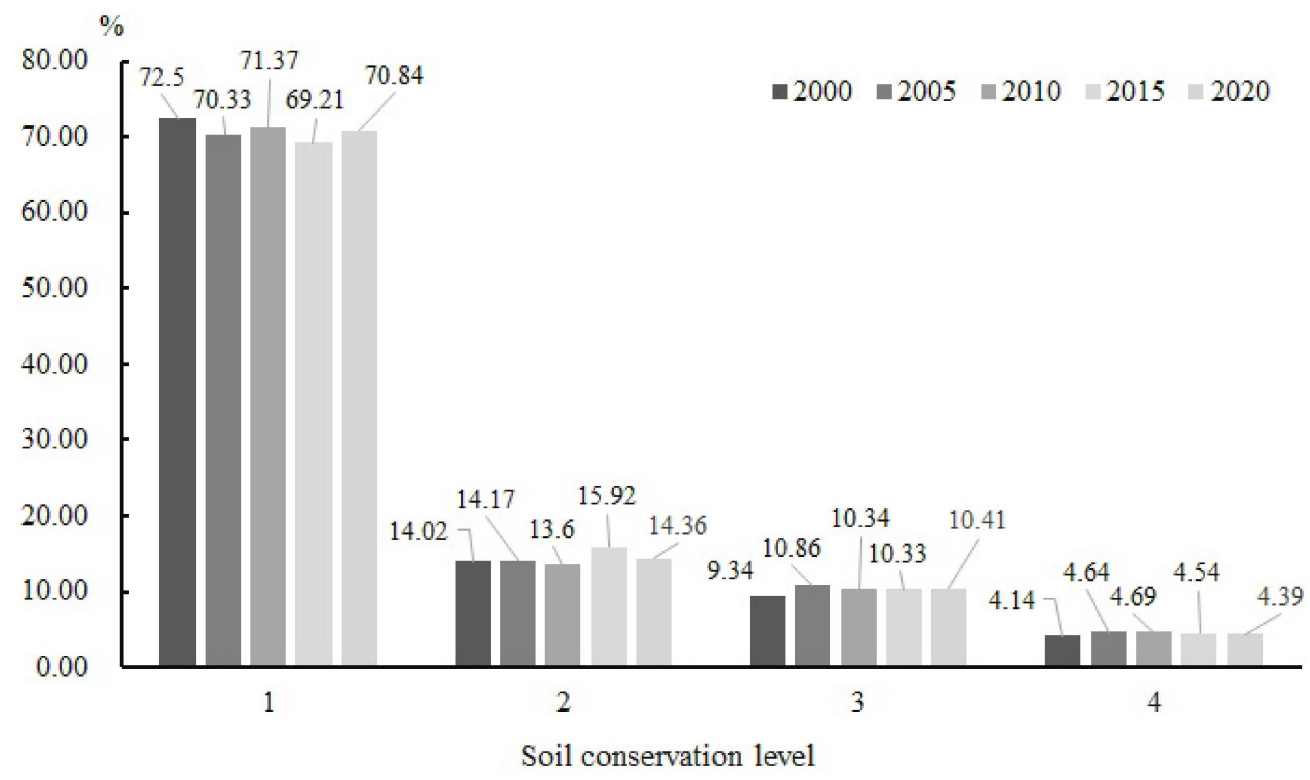

Figure 7. Proportion of SC grade in HRB from 2000 to 2020.

Incorporating the analysis of land use, the expanded utilization of cropland and forest land has brought an increase in SC in the upper and the middle regions. However, the main body to provide SC supply was grassland throughout the whole basin. The areas decrease in grassland caused the decline of SC. At the same time, the growth of cropland and the reduction in unused land compensated the loss of SC caused by the area drop of grassland to some extent. So, in terms of total volume, the soil holds in the study area showed a slight upward trend from 2000 to 2015, followed by a downward trend from 2015 to 2020 . 


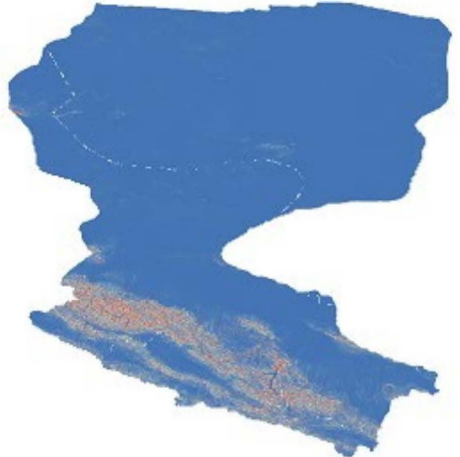

(a) 2015

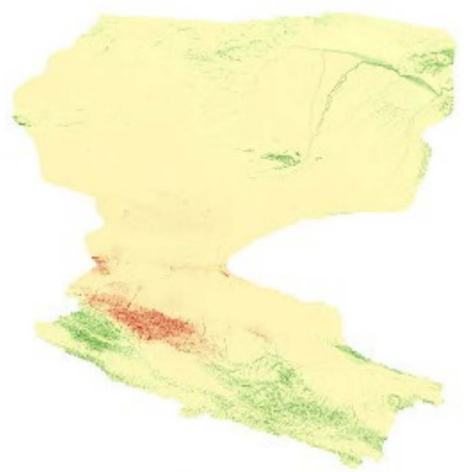

(d) 2010-2015

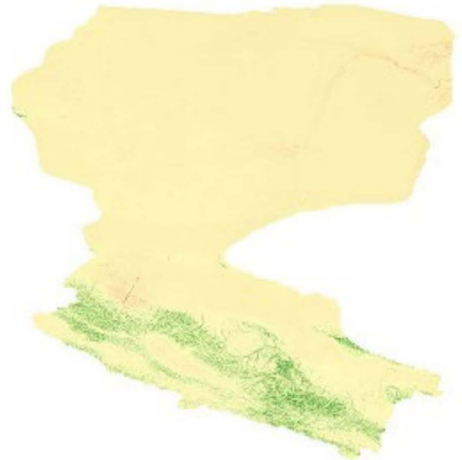

(b) 2000-2005

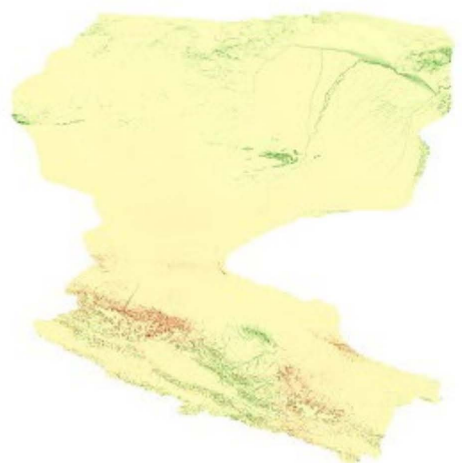

(e) 2015-2020

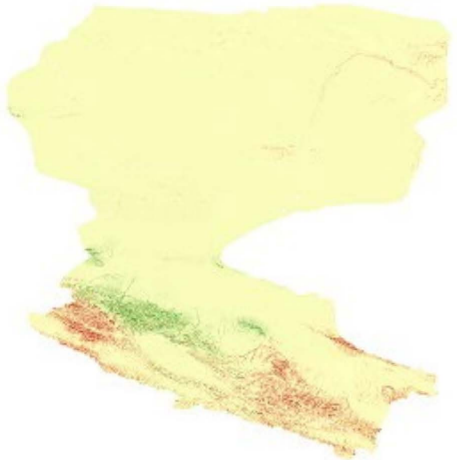

(c) 2005-2010

Soil conservation $/(\mathrm{t} \cdot \mathrm{hm}-2)$

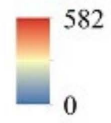

Difference value/(t-hm-2)
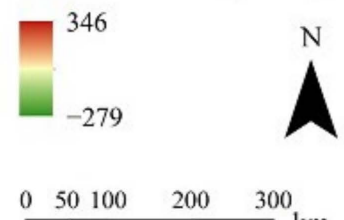

Figure 8. Variation of SC in HRB from 2000 to 2020. (a) Spatial distribution of SC in 2015; (b)-(e) four difference maps of the five-year changes.

\subsection{TGE of Different ESs}

In order to analyze the TGE of different ESs, 2015-HRB was selected to conduct this practice.

\subsubsection{Terrain Niche Index of HRB}

The slope and the elevation data were extracted from DEM, and the topographic index of HRB was calculated by the terrain niche index formula-14 (Figure 9). It was divided into six levels: one (0.179-0.305), two (0.305-0.463), three (0.463-0.709), four (0.709-1.005), five $(1.005-1.282)$, and six $(1.282-1.786)$. The topography was dominated by one and two levels, the area of which accounts for $70.96 \%$ of the whole basin. As seen from the spatial distribution (Figure 10), the topographic index was low in the south (east) and high in the north (west). In other words, the high-grade topographic level was concentrated in the upper and middle reaches of the basin, while low- and medium-level terrain areas were heavily distributed in the north of midstream region and throughout the downstream region. 


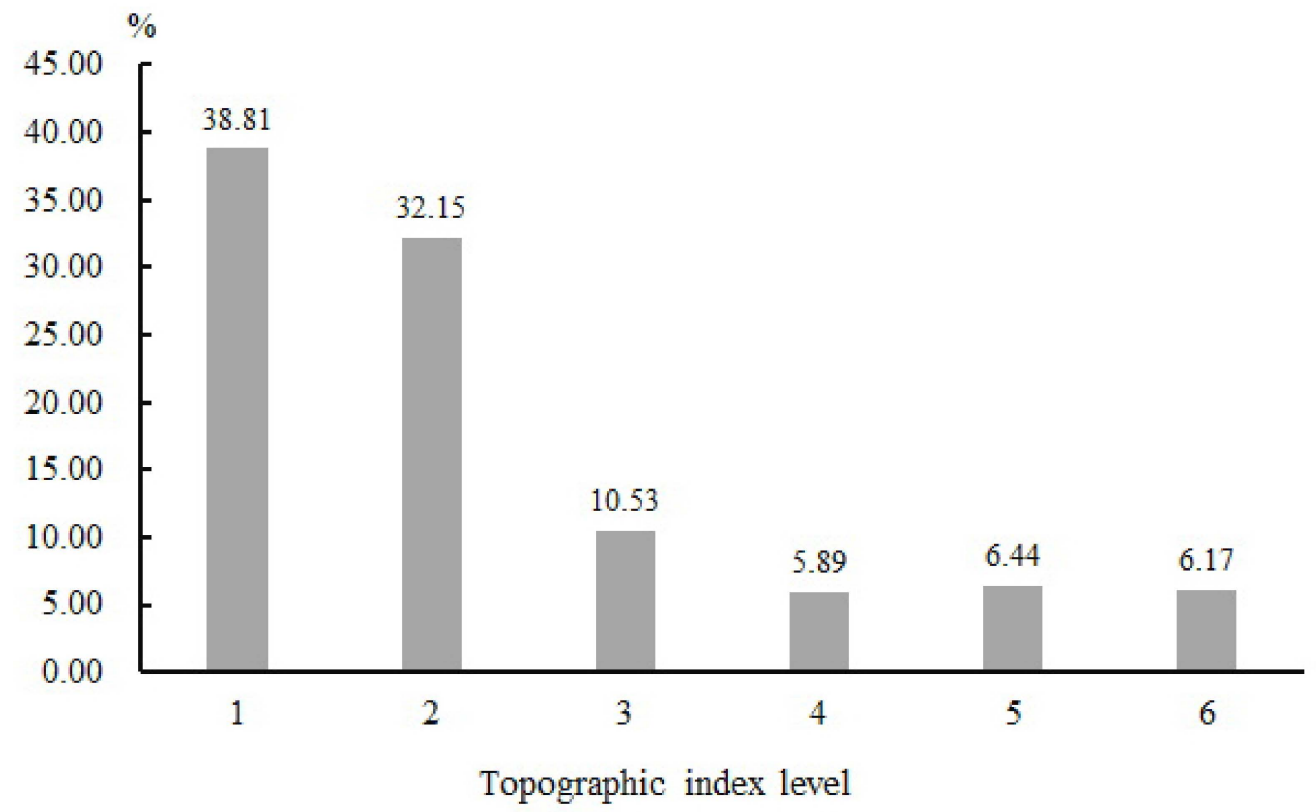

Figure 9. Proportion of different topographic positions index in HRB.

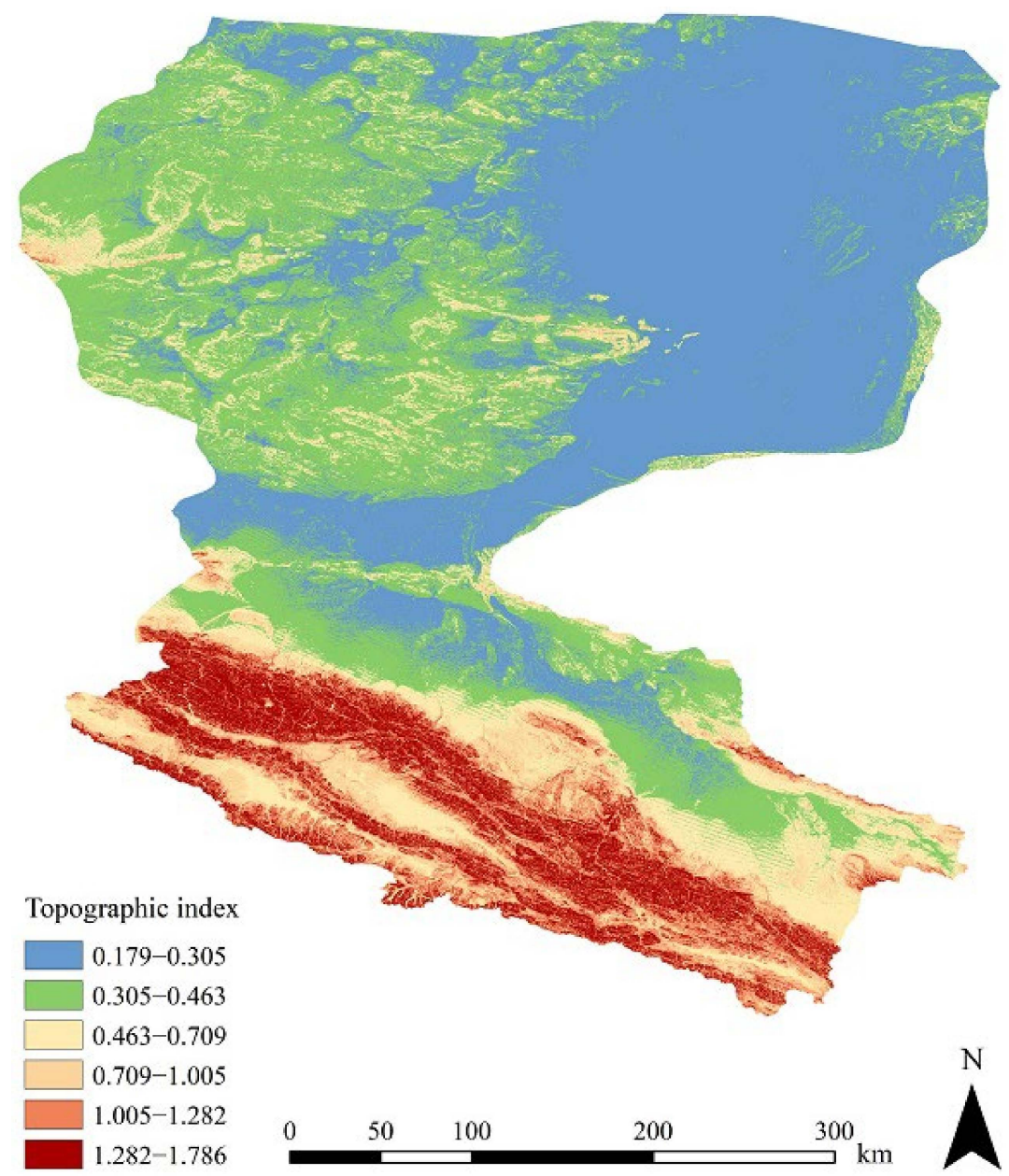

Figure 10. Spatial distribution of topographic position index in HRB in 2015.

\subsubsection{TGE of $\mathrm{HQ}$}

The HQ was reclassified into four levels: one (0-0.3), two (0.3-0.5), three (0.5-0.8), and four (0.8-1), which correspond to poor, general, high, and higher grades (see Section 3.1.1), 
respectively. The scatter plot was obtained by the statistical re-regression analysis on the HQ and topographic index (Figure 11). The HQ in the HRB has an upward trend with the growth of the topographic index, and there is a significant positive correlation between the two. The curve fitting $\left(R^{2}\right)$ is 0.441 , indicating that the logarithmic function can effectively describe their relationship.

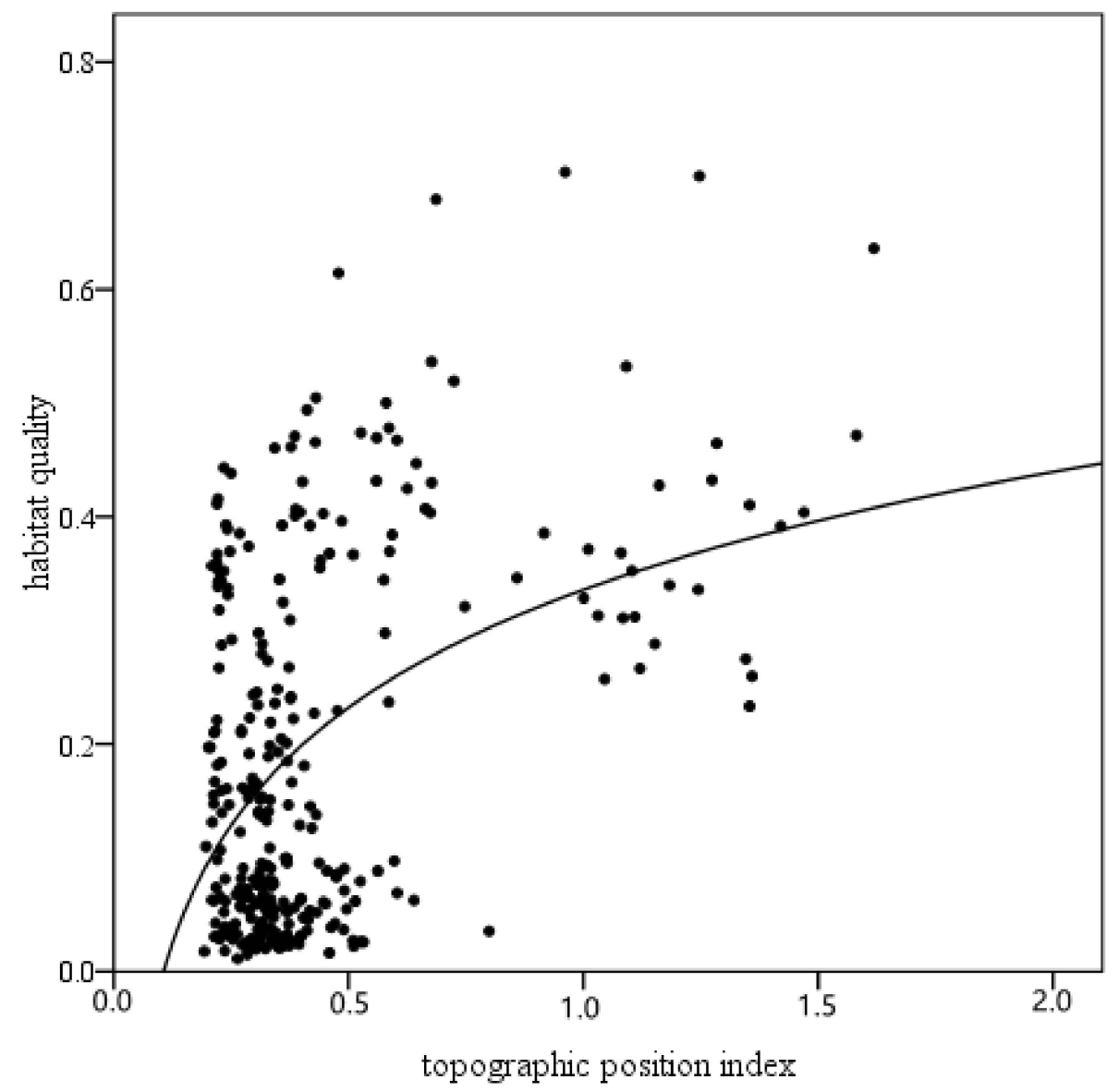

Figure 11. Correlation between terrain index and HQ in HRB in 2015.

As can be seen from Figure 12, the majority of low-grade habitat mass was distributed in the low-grade topographic index in HRB in 2015. With the growth of the topographic level index, the low-quality habitat area gradually reduced with the area increase in highquality habitats. Additionally, it can be clearly seen that the proportion of high-grade HQ significantly increased with the growth of the terrain niche index from the proportion of change matrix during 2000-2015 (Table 3). The dominant interval was the third HQ level for the fourth and fifth levels of the terrain index, while the other levels of terrain were the first level of HQ. Over the past 15 years, the HQ of second- and fourth-grade topography positions declined. By incorporating land-use changes, this appearance was caused by the decrease in grassland and the increase in built-up land and unused land. Conversely, the increase in HQ at other topographical levels was caused by the increase in cropland and the decrease in unused land. It is sufficient to show that the transformation of nature has a considerable impact on HQ. Therefore, under the impact of rapid urbanization on ecological environment in this basin, relevant departments should take some ecological measures to deal with this. 


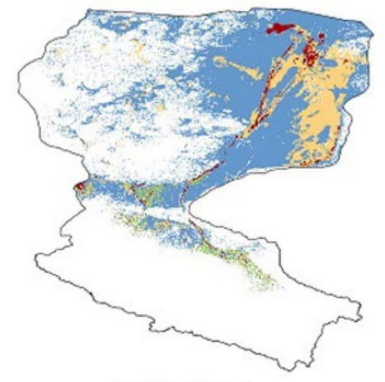

(a) First level

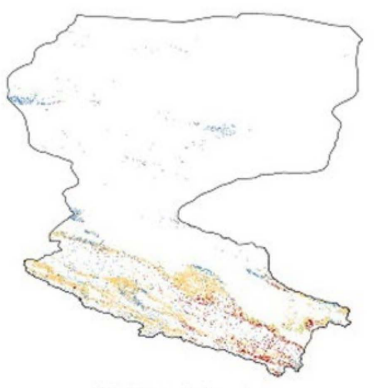

(d) Fourth level

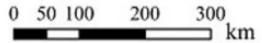

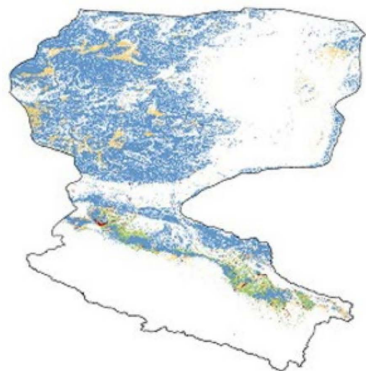

(b) Second leve

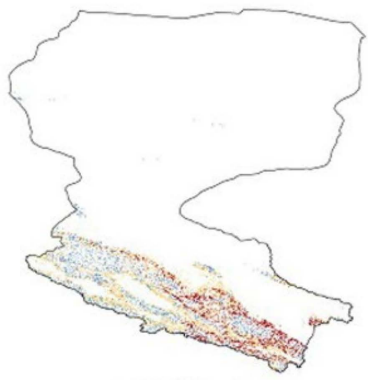

(e) Fifth level

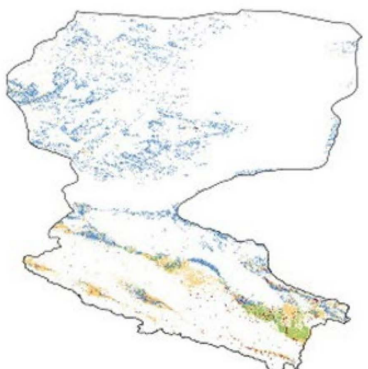

(c) Third level

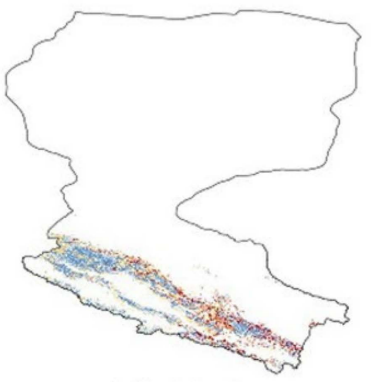

(f) Sixth level

Habitat quality level

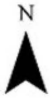

Figure 12. Spatial distribution of HQ at various topographic levels in HRB in 2015.

Table 3. Proportion of HQ distribution at different topographic locations (2000/change value from 2000 to 2015) (\%).

\begin{tabular}{cccccccccc}
\hline \multirow{2}{*}{$\begin{array}{c}\text { Terrain Niche } \\
\text { Index Level }\end{array}$} & \multicolumn{7}{c}{ HQ Level } \\
\cline { 2 - 10 } & \multicolumn{2}{c}{$\mathbf{1}$} & \multicolumn{2}{c}{$\mathbf{2}$} & \multicolumn{3}{c}{$\mathbf{3}$} \\
\hline 1 & 75.05 & -0.99 & 2.58 & 0.64 & 19.20 & 0.26 & 3.17 & 0.05 \\
2 & 84.33 & -0.36 & 4.37 & 0.59 & 10.64 & -0.32 & 0.65 & 0.03 \\
3 & 58.65 & -0.11 & 9.34 & 0.35 & 28.95 & 0.03 & 3.07 & -0.16 \\
4 & 22.93 & 0.20 & 2.18 & 0.13 & 62.90 & -1.13 & 11.99 & 0.33 \\
5 & 27.61 & 0.34 & 0.35 & 0.02 & 49.02 & 0.15 & 23.02 & -0.56 \\
6 & 49.51 & -0.82 & 0.04 & 0.01 & 32.77 & 0.60 & 17.68 & 0.68 \\
\hline
\end{tabular}

\subsubsection{TGE of $W Y$}

The water depth in the basin was divided into four levels based on the raster data obtained from model (see Section 3.1.2). The scatter plot was obtained by the statistical re-regression analysis of WY and the topographic index (Figure 13). The WY in the HRB has an upward trend with the growth of the topographic index. There is a significant positive correlation between the two. The curve fitting $\left(R^{2}\right)$ is 0.566 , which indicates that the logarithmic function can successfully describe their relationship. The overlaid spatial distribution of the terrain niche index and WY shows the distinct discrepancy in the distribution of water depth levels on the local shape level index in HRB in 2015 (Figure 14). Similar to the distribution of HQ with the local level index, the WY distributed in the lowterrain-level index areas significantly decreased. With the growth of the topographic level index, the depth of water production also gradually increased. There was little low-grade water depth in the areas of the sixth topographic level index. 


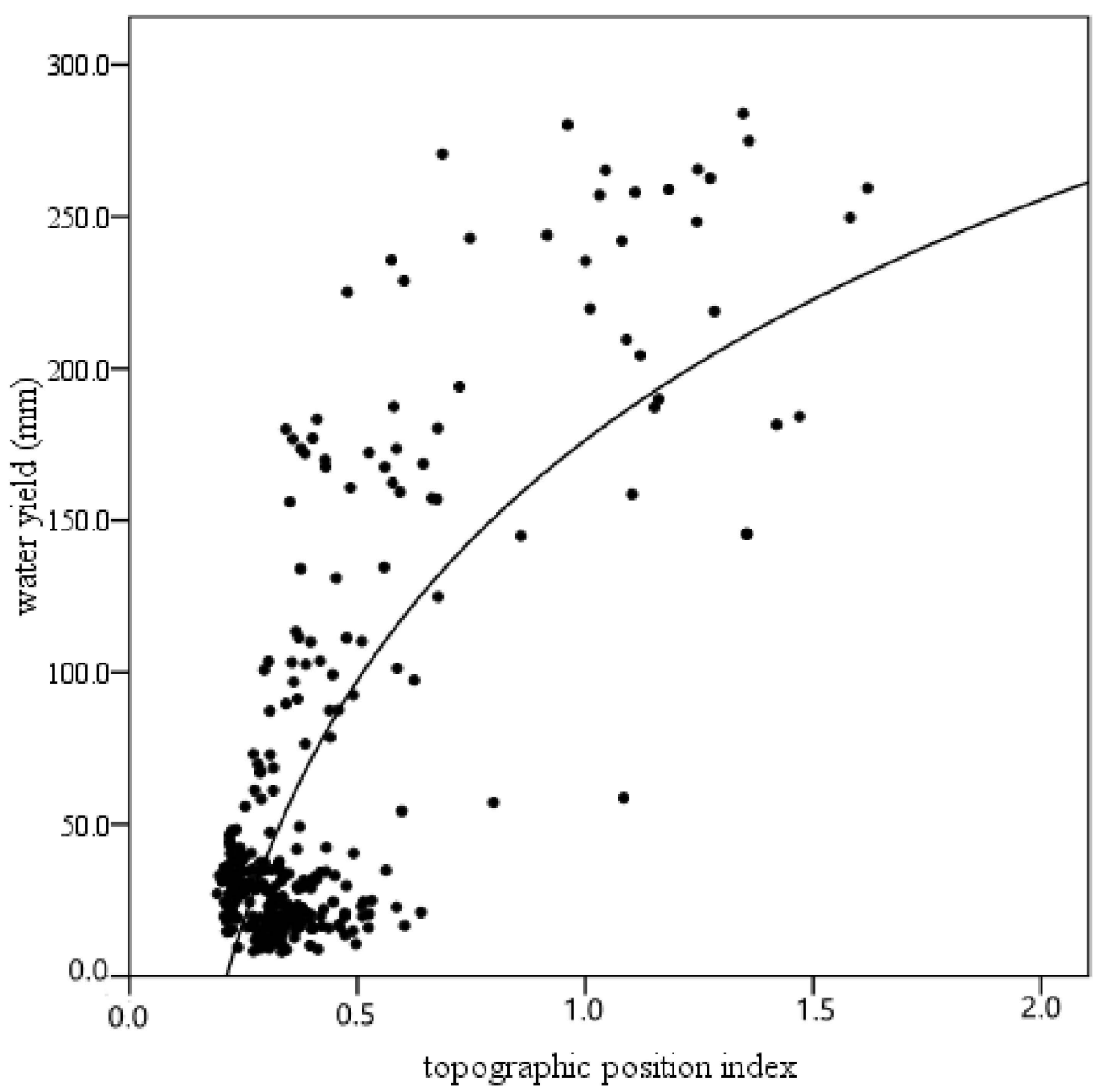

Figure 13. Correlation between terrain index and WY in 2015.

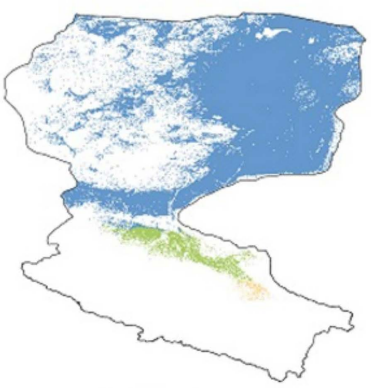

(a) First level

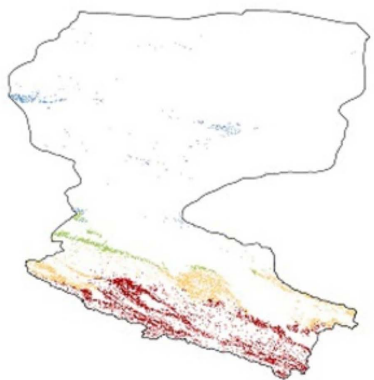

(d) Fourth level

\begin{tabular}{l}
$0 \quad 50 \quad 100 \quad 200 \quad 300$ \\
\hline
\end{tabular}

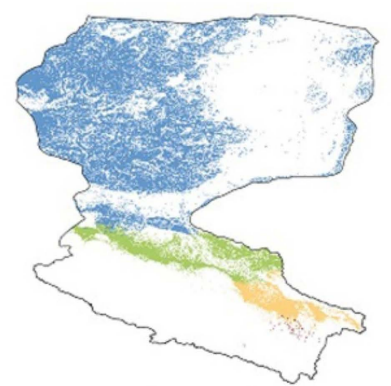

(b) Second level

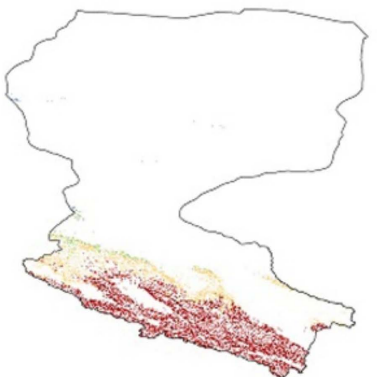

(e) Fifth level

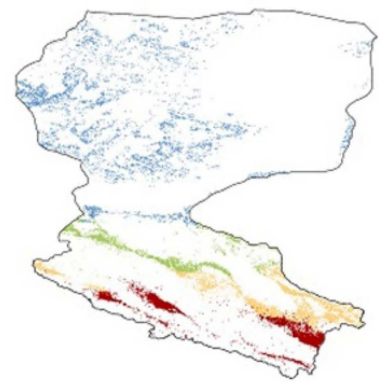

(c) Third level

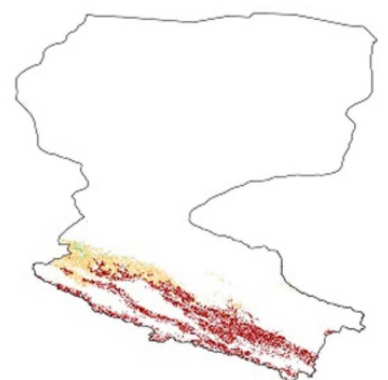

(f) Sixth level Water yield level

Figure 14. Spatial distribution of WY depth at various topographic levels in HRB in 2015. 
The regional statistics of topographic level can be obtained based on the spatial distribution of WY in each year (Table 4). WY in the low terrain level was dominated by the low depth of first and second levels. The water production depth increased to three or four levels in this basin when it raised to fifth and sixth topographic indexes. This is enough to show that WY is closely related to the topographic gradient. The reason for this is that land use in low-terrain areas is majorly unused land with low grassland cover and low water conservation. High-terrain areas mostly have with medium- and high-density grassland cover, and the climate is humid at higher altitudes, resulting in higher water production. Comparing the water depth of 2015 with that of 2000, a decline in the water depth of the low-grade topographic index and the increase in water-producing depth of medium- and high-level topographic index areas was found. In addition to the differential rainfall, this difference may be due to the increasing area of grassland and forest land cover in high-altitude and high-terrain areas. The ecological environment in the unused land of the desert-dominated region continues to deteriorate in the north due to the continuous and extensive human activities. This needs to arouse people's vigilance with regard to, e.g., reducing human extrusion of original animal and plant living space, improving bad ecological environments, and maintaining good surroundings together.

Table 4. Distribution proportion of WY in different topographic levels (2000/change value from 2000 to 2015$)(\%)$.

\begin{tabular}{cccccccccc}
\hline \multirow{2}{*}{$\begin{array}{c}\text { Terrain Niche } \\
\text { Index Level }\end{array}$} & \multicolumn{7}{c}{ WY Level } \\
\cline { 2 - 10 } & \multicolumn{2}{c}{$\mathbf{1}$} & \multicolumn{2}{c}{$\mathbf{2}$} & & $\mathbf{3}$ & \multicolumn{4}{c}{$\mathbf{4}$} \\
\hline 1 & 97.75 & -3.57 & 2.25 & 0.01 & 0.00 & 0.50 & 0.00 & 0.00 \\
2 & 84.29 & -4.23 & 14.52 & -0.04 & 1.19 & 5.38 & 0.00 & 0.13 \\
3 & 42.26 & 1.58 & 25.08 & 0.19 & 25.95 & -1.23 & 6.71 & 10.40 \\
4 & 4.69 & 1.43 & 16.72 & -0.03 & 43.63 & -7.87 & 34.96 & 13.42 \\
5 & 0.21 & 0.61 & 4.98 & -0.03 & 35.41 & -8.89 & 59.41 & 8.84 \\
6 & 0.01 & 0.01 & 1.61 & 0.00 & 28.41 & 3.60 & 69.97 & -4.43 \\
\hline
\end{tabular}

\subsubsection{TGE on SC}

The scatter plot was obtained by the statistical re-regression analysis of SC and the topographic index (Figure 15). The SC in the HRB has an upward trend with the increase in the topographic index, and there is a significant positive correlation between the two. The curve fitting $\left(R^{2}\right)$ is 0.687 , indicating that the logarithmic function can properly describe their relationship.

As seen in Figure 16, it was in a poor condition for the whole basin in 2015. However, it can also be seen that the TGE of SC is similar to that of HQ and WY, although the SC in different locations is primarily of a low grade. The SC gradually became better with the increase in the terrain niche index. Furthermore, in order to analyze the proportions of each part, the SC was divided into four levels using the natural break point method (Table 5) and was then overlaid with the terrain niche index. Most of the low-grade areas transformed into high-grade areas and the proportion decreased gradually with the increase in the terrain niche index. This is mainly due to the concentration of high-terrain zones in the upper reaches of the basin, which have large areas of forest land, grassland and cropland, as well as dense vegetation and thick and fertile soil. The downstream area was dominated by desert ecosystems, with sparse vegetation and poor soil. The area proportion of low soil levels in various shapes decreased slightly, while that of high-grade soil levels increased. However, soil conditions in the basin remained poor and large amounts of soil were at risk of erosion, particularly in the southern mountainous areas and unused land in the north. Administrators should develop reasonable management measures. Only by strengthening the protection of woodland and grassland, planting trees and expanding vegetation cover can we reduce the threat of soil erosion and decrease the harm. 


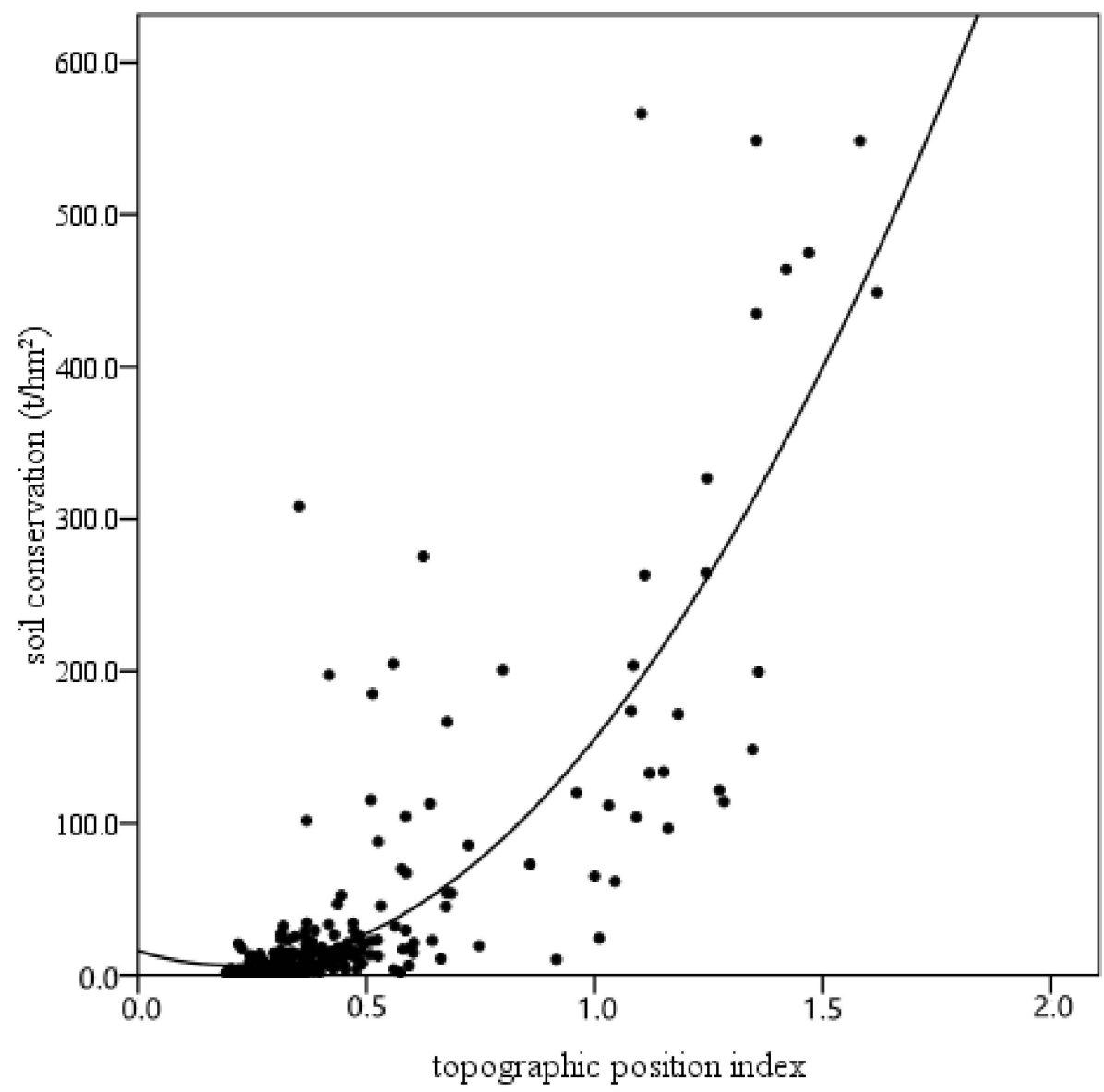

Figure 15. Correlation between terrain index and SC in 2015.

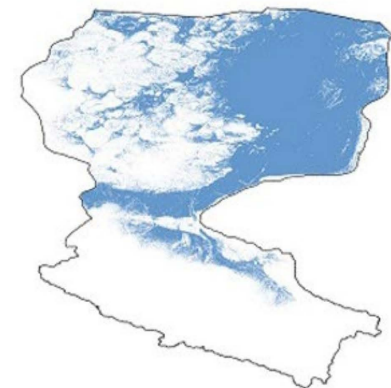

(a) First level

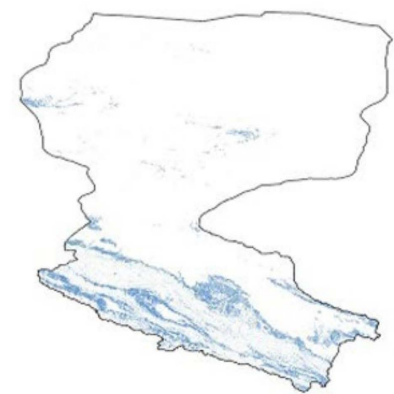

(d) Fourth level

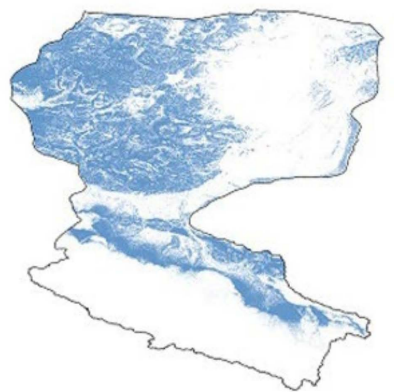

(b) Second level

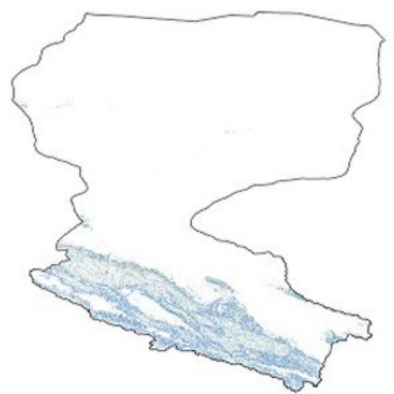

(e) Fifth level

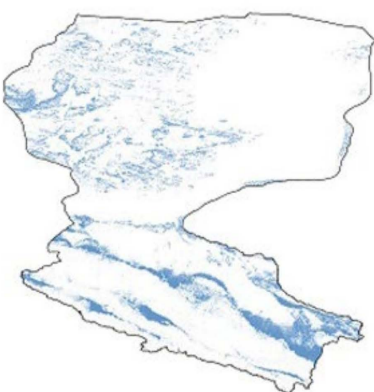

(c) Third level

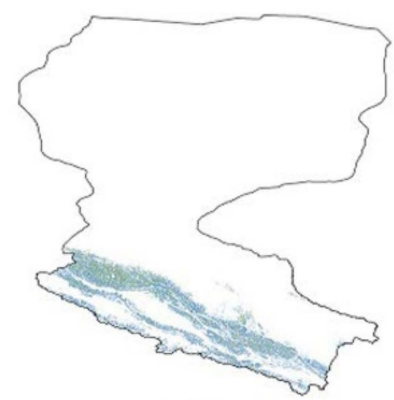

(f) Sixth level

Soil conservation level

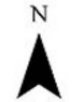

Figure 16. Spatial distribution of SC at various topographic levels in HRB in 2015. 
Table 5. Distribution proportion of SC at different topographic levels (2000/change value from 2000 to 2015$)(\%)$.

\begin{tabular}{ccccccccc}
\hline \multirow{2}{*}{$\begin{array}{c}\text { Terrain Niche } \\
\text { Index Level }\end{array}$} & \multicolumn{7}{c}{ SC Level } \\
\cline { 2 - 9 } & \multicolumn{2}{c}{$\mathbf{1}$} & \multicolumn{2}{c}{$\mathbf{2}$} & & $\mathbf{3}$ & & $\mathbf{4}$ \\
\hline 1 & 99.83 & -2.70 & 0.14 & 0.07 & 0.03 & 0.10 & 0.01 & 2.53 \\
2 & 99.75 & -1.73 & 0.20 & 0.96 & 0.04 & 0.02 & 0.01 & 0.75 \\
3 & 98.45 & 0.39 & 1.38 & -0.58 & 0.12 & -0.04 & 0.05 & 0.23 \\
4 & 92.42 & -2.33 & 7.24 & -0.03 & 0.23 & 1.13 & 0.11 & 1.23 \\
5 & 90.12 & 1.62 & 8.68 & -2.65 & 1.07 & 0.29 & 0.13 & 0.74 \\
6 & 81.21 & -4.91 & 12.70 & 3.24 & 0.83 & -0.37 & 0.18 & 2.04 \\
\hline
\end{tabular}

\section{Discussion}

In this study, we evaluated the changes in ES patterns in the HRB from 2000 to 2020 by using the three sub-modules in the InVEST model. The spatial variations of $\mathrm{HQ}, \mathrm{WY}$ and SC were revealed for the past 20 years. We also analyzed the distribution characteristics of three ESs from the perspective of topography. This can provide the scientific basis for optimizing regional ecosystem patterns and land-use planning and management. The results are of great significance for rational planning of land use and constructing ecological civilizations.

\subsection{Validation of Results with Previous Works}

In general, the overall trends of the spatiotemporal changes of ESs are the same compared with the similar studies in the region [52,57]. Therefore, the reliable results can objectively mirror the spatial differentiation characteristics of ESs in the HRB. Otherwise, elevation and slope were used to analyze the changes in ESs on different terrain gradients and the results illustrate different ESs showing obvious TGE in the HRB. The distribution pattern of ESs is generally high in the mountainous areas and low in the plain, which is consistent with the relevant research $[60,61]$. In order to further verify the accuracy and reliability of the results, some specific cross-validations were conducted between this paper and previous studies [62,63], including the values of different ESs and spatial distributions (Table 6). The range of HQ in this result is the same with the referenced work. It shows complete consistency with the distribution of high values and low values. The WY value in our study is slightly higher than that in the referenced work, but the difference is within a reasonable range. The major spatial differentiation is that the high value in our work is continuously distributed in the south of middle reaches, while it is dispersed with fragments in the referenced study. This may be due to different methods used to calculate the potential evapotranspiration in the two studies. Additionally, owing to lacking SC in previous studies in HRB, research from 2011 was selected to compare with our results in 2010. The result of this study is numerically low. The spatial difference lies in the shortage of high-value areas for SC in the northern basin and the distribution is not obvious along the riverside. This may be the factor parameter difference in the biophysical coefficient table. In addition, different formulas used to calculate the $K$ factor in the two studies may also cause a discrepancy in the final outcomes. 
Table 6. Comparison between the results in this paper and those in the referenced work.

\begin{tabular}{|c|c|c|c|c|}
\hline \multirow{2}{*}{$\begin{array}{c}\text { ESs } \\
\text { Supply }\end{array}$} & \multicolumn{4}{|c|}{ Results in This Paper } \\
\hline & Year & Area & Range & Spatial Distribution \\
\hline HQ & 2015 & $\begin{array}{l}\text { Midstream (by provincial } \\
\text { boundaries) }\end{array}$ & $0.0-1.0$ & $\begin{array}{l}\text { General and higher in the central region while } \\
\text { poor in the northern and southern regions }\end{array}$ \\
\hline WY & 2000 & $\begin{array}{l}\text { Midstream (by provincial } \\
\text { boundaries) }\end{array}$ & $0.0-314.7 \mathrm{~mm}$ & $\begin{array}{l}\text { More southeast, less northwest; obvious } \\
\text { difference between the north-south and } \\
\text { continuous distribution of high-value areas }\end{array}$ \\
\hline SC & 2010 & HRB & $0-644 \mathrm{t} / \mathrm{hm}^{2}$ & $\begin{array}{l}\text { More west and less east, more south and less } \\
\text { north; high-value concentrated area in the } \\
\text { southern part of middle reaches }\end{array}$ \\
\hline \multirow{2}{*}{$\begin{array}{c}\text { ESs } \\
\text { Supply }\end{array}$} & \multicolumn{4}{|c|}{ Results in Referenced work } \\
\hline & Year & Area & Range & Spatial Distribution \\
\hline HQ & 2015 & $\begin{array}{l}\text { Midstream (by Yingluo } \\
\text { gorge and Zhengyi gorge) }\end{array}$ & $0.0-1.0$ & $\begin{array}{l}\text { General and higher-grade in the central and } \\
\text { southern regions while poor in the northern } \\
\text { regions }\end{array}$ \\
\hline WY & 2000 & $\begin{array}{l}\text { Midstream (by Yingluo } \\
\text { gorge and Zhengyi gorge) }\end{array}$ & $0.0-306.0 \mathrm{~mm}$ & $\begin{array}{c}\text { More southeast, less northwest; Dispersed } \\
\text { distribution of high value areas }\end{array}$ \\
\hline SC & 2011 & HRB & $0-646 \mathrm{t} / \mathrm{hm}^{2}$ & $\begin{array}{l}\text { More west and less east; Sparse distribution } \\
\text { of high-value areas along the riverside in the } \\
\text { north and south basin }\end{array}$ \\
\hline
\end{tabular}

\subsection{Driving Forces of ESs Variation}

The changes of ESs are affected by natural and human factors. Climate change is the main driving issue for natural factors. Furthermore, human factors, such as activity intensity on different topographic gradient will also have an important impact on ESs [64]. We qualitatively analyze the natural and human factors of ES changes in the HRB in terms of temperature, precipitation and human activities.

Research indicated that the temperature in the HRB shows a significant upward trend in the recent decades [65]. The increase rate of temperature in the study area is much higher than that of the average in the northern hemisphere during the same period. In particular, a large increase in temperature around 2010 was rare [66]. Rising temperature will promote the conversion of some unused land covered by glaciers and snow into grassland and grassland into woodland in the basin. The general trend of precipitation is increasing but the magnitude is negligible. The change is not obvious. The precipitation in this basin is not enough to balance the increase in evapotranspiration caused by the rising temperature. This gave rise to a further reduce in surface water, while the glacier melt water alleviated the decrease in runoff [66]. So, runoff changes little as temperature rises. The water supply gradually decreased, and some rivers and lakes dried up. The water area shrunk and desertification increased significantly [67].

Human activity is another essential driving force for land-use change in the watersheds. As be seen from Table 7, urban and rural industrial and other residential land continue to expand with the gradual deepening of human influence over the past 20 years. A large amount of unused land and grassland were reclaimed as arable land due to more intensive human activities in the middle reaches, which causes the area growth of cropland significantly. On the other hand, the manual allocation of water resources has given rise to a large amount of water diversion to the downstream region of the HRB. As a result, some unused land has been restored to grasslands. The ecological environment has been remarkably improved. A series of ecological management measures, such as natural forest and grass fence enclosures, have provoked the area increase in forest land in the upstream and the midstream areas. However, the growth of the population has brought about an increase in water demand. Then, adding up the decrease in rainfall, forest land and grassland shows a degradation trend in some areas. Therefore, the land-use change in 
the watersheds is a result of the joint power of human activities and climate change [37]. Furthermore, the land-use change will have an impact on the variation of different ESs.

Table 7. Area of land use in different reaches of HRB from 2000 to $2020\left(\mathrm{~km}^{2}\right)$.

\begin{tabular}{|c|c|c|c|c|c|c|}
\hline \multirow{2}{*}{ Land-Use Type } & \multicolumn{3}{|c|}{2000} & \multicolumn{3}{|c|}{2005} \\
\hline & Upstream & Midstream & Downstream & Upstream & Midstream & Downstream \\
\hline Cropland & 11.66 & 4617.33 & 60.41 & 11.66 & 4939.70 & 69.22 \\
\hline Forest & 1487.75 & 2950.35 & 878.84 & 1487.75 & 2941.53 & 870.45 \\
\hline Grassland & 5457.08 & $13,654.56$ & $11,069.79$ & 5457.08 & $13,598.84$ & $11,053.02$ \\
\hline Waters & 228.56 & 805.92 & 332.60 & 228.56 & 803.08 & 356.77 \\
\hline Built-up land & 10.24 & 414.33 & 135.16 & 10.24 & 449.15 & 135.19 \\
\hline Unused land & 2756.17 & 33684.40 & $54,012.44$ & 2757.61 & $33,394.58$ & $54,003.63$ \\
\hline \multirow{2}{*}{ Land-Use Type } & \multicolumn{3}{|c|}{2010} & \multicolumn{3}{|c|}{2015} \\
\hline & Upstream & Midstream & Downstream & Upstream & Midstream & Downstream \\
\hline Cropland & 10.24 & 4959.17 & 66.95 & 10.24 & 5255.53 & 65.53 \\
\hline Forest & 1513.77 & 2933.15 & 845.86 & 1511.92 & 2932.72 & 823.55 \\
\hline Grassland & 5459.92 & $13,631.82$ & $11,046.05$ & 5459.92 & $13,535.16$ & $11,170.57$ \\
\hline Waters & 217.90 & 799.38 & 388.32 & 216.48 & 870.45 & 377.66 \\
\hline Built-up land & 10.24 & 452.43 & 135.12 & 10.24 & 572.25 & 133.33 \\
\hline Unused land & 2755.76 & $33,327.20$ & $54,016.13$ & 2758.23 & $32,937.04$ & $53,806.20$ \\
\hline \multirow{2}{*}{ Land-Use Type } & \multicolumn{3}{|c|}{2020} & & & \\
\hline & Upstream & Midstream & Downstream & & & \\
\hline Cropland & 16.45 & 6217.98 & 76.42 & & & \\
\hline Forest & 1401.17 & 3292.52 & 876.20 & & & \\
\hline Grassland & 5732.36 & $14,570.27$ & $11,568.41$ & & & \\
\hline Waters & 188.73 & 921.64 & 386.24 & & & \\
\hline Built-up land & 12.24 & 641.19 & 116.89 & & & \\
\hline Unused land & 2616.08 & $30,459.55$ & $53,352.68$ & & & \\
\hline
\end{tabular}

\subsection{Suggestions for Sustainable Improvement of ESs}

The implementation of ecological protection policies and effective management in the Qilian Mountain reserve have enhanced the grassland coverage and water conservation capacity in the upstream area over the years. The Forestry Bureau should continue to strengthen the protection and surveillance of forest and grassland [68]. In the upper mountain region, climate change is always a dominant element for water resource allocation. Furthermore, except for water conservation, the increase in forest and grassland will also play an important role in adjusting runoff in the form of transpiration interception due to the warming and drying trend in recent years [69,70]. Grass planting and forestation measures should also be taken under the guidance of the Forestry Bureau within a scientific and reasonable range to stabilize runoff according to local conditions. In addition, thoughtful reservoir construction by the Water Resources Bureau is also useful in the regulation of seasonal runoff and in the efficient implementation of the ecological water diversion project.

The optimization and adjustment of the agricultural planting structure have been implemented in the midstream area in recent years, which yielded preliminary results for the construction of a water-saving society. However, the rapid development of the agricultural economy has brought the expansion of the irrigation area, which has caused the increase in water consumption, offsetting the consequences of saving water [70]. According to the analysis of long-term climate change in the basin, runoff may turn into the dry season in the future [71]. The implementation of the water transfer project may not be enough to support the rapid growth of population and fast development of the agricultural economy in the middle reaches [69-72]. In order to adapt to the changes in water resources in various stages, it is necessary to control the cropland expansion in the midstream region as soon 
as possible and the Bureau of Land Management needs to adjust the industrial structure. Moreover, during the implementation of the Heihe River "97" water diversion scheme, the continuous expansion of the oasis has begun to consume a large amount of groundwater and the ecological environment has a tendency of degradation [70]. It is essential to strictly limit the exploitation of groundwater, make zoning planning and continue to implement ecological protection projects in fragile ecological environment areas by the Natural Resources Planning Bureau. This basin needs to develop urbanization without destroying natural environment and follow the principles of sustainable development.

Since the implementation of the Heihe River "97" water diversion scheme in 2000, the amount of water flowing into the downstream region has increased significantly. The water area gradually recovered and steadily expanded, and the growth of vegetation improved. This alleviated the deterioration of the ecological environment in the downstream area, remarkably restored the ecological environment and initially realized the control goal $[69,73]$. However, the continuous expansion of cropland and construction land still brings great pressure on the environment. So, to improve ecological conditions, the Environmental Protection Agency should strictly control overgrazing and deforestation to allow the selfhealing function of the ecosystem to take place. According to the local conditions, planting trees and grass can alleviate the ecological deterioration of desert. The government should further optimize and adjust the amount of water allocation and conduct a more reasonable allocation of resources for the sustainable development of the basin.

\subsection{Limitations and Future Study}

Although some reliable results have been obtained in this study, we recognize some limitations of this research. First of all, more attention should be paid in future studies. For example, only three key services provided by the ecosystems in the HRB were considered in our study due to the urgency to solve eco-environmental problems, such as the deterioration of the ecological environment, shortage of water resources and soil erosion. At the same time, the eco-environmental characteristics and data availability of the research area were also taken into consideration. However, the temporal and spatial changes of other ESs in the basin cannot be ignored, and they can be further discussed in future research. Then, the terrain niche index was used to comprehensively mirror the effect of topography on ESs. However, the respective weights of elevation and slope in the impact is not clear, and this needs to be further explored so as to formulate more practical ecological protection policies. Additionally, distinct operation mechanisms of different models may result in dissimilar outputs. It is necessary to focus on the comparative verification of the evaluated results between various models in future work.

\section{Conclusions}

In this study, three key ESs (e.g., HQ, WY and SC) were evaluated using the InVEST model in HRB from 2000 to 2020, and the TGE of different ESs was analyzed based on the terrain niche index. First of all, HQ and SC in the basin improved overall, while WY was in continuous decline. The values of various ESs changed little and the spatial distribution of them always presented similar discrepancy laws. The distribution of ESs in the basin shows lower values in the north and higher values in the south, high values at upstream areas and low values at downstream area. Furthermore, the correlations between different ESs and topography are strong, showing obvious TGE. HQ, WY and SC increased with the growth of the topographic level index. A high-quality habitat has high rates of water production. A low-quality habitat has a low yield of water. High SC is mostly distributed in the mountainous hilly areas with high grassland coverage, while a low SC is related to the accumulation of built-up land and unused land.

We analyze the variation of different ESs on the two scales: watersheds and substream. Relevant suggestions should be adopted for the distinct changes of ESs on different scales. In addition, topography and land use were combined to analyze the ES variation; in particular, the terrain niche index was specifically used to analyze the influence of 
TGE on different ESs. The results provide useful information for policy proposals to comprehensively consider the effect of terrain factors on the spatial differences of Ess and its drivers. The method provides a new perspective for studying the spatial differentiation of various ecological problems in the inland watersheds and can be applied to other similar areas, and then be incorporated into the formulation of watershed ecological zoning management policies.

Author Contributions: Conceptualization, L.Z. and N.H.; methodology, L.Z. and N.H.; software, L.Z.; validation, L.Z. and N.H.; formal analysis, L.Z.; data curation, L.Z.; writing-original draft preparation, L.Z.; writing-review and editing, L.Z. and N.H.; supervision, N.H. All authors have read and agreed to the published version of the manuscript.

Funding: This research was funded by the National Natural Science Foundation of China (No. 41701478) and by the Fundamental Research Funds for the Central Universities (No. GK201903069).

Institutional Review Board Statement: Not applicable.

Informed Consent Statement: Informed consent was obtained from all subjects involved in the study.

Data Availability Statement: Data sharing not applicable.

Acknowledgments: We thank the useful suggestions from the editors to improve this work. We also appreciate the constructive comments from the two anonymous reviewers that greatly improved this manuscript.

Conflicts of Interest: The authors declare no conflict of interest.

\section{References}

1. Fu, B.; Zhou, G.; Bai, Y.; Song, C.; Liu, J.; Zhang, H.; Lü, Y.; Zheng, H.; Xie, G. The main terrestrial ecosystem services and ecological security in China. Adv. Earth Sci. 2009, 24, 571-576. [CrossRef]

2. Chen, Y.-F.; Zhou, J.-X.; Xiao, J.; Li, Y.-P. Forecasting loss of ecosystem service value using a BP network: A case study of the impact of the South-to-north Water Transfer Project on the ecological environmental in Xiangfan, Hubei Province, China. Biomed. Environ. Sci. 2003, 16, 379-391. [CrossRef] [PubMed]

3. Zhang, H.; Wang, Q.; Li, G.; Zhang, H.; Zhang, J. Losses of ecosystem service values in the Taihu Lake Basin from 1979 to 2010. Front. Earth Sci. 2017, 11, 310-320. [CrossRef]

4. Wang, C.; Li, X.; Yu, H.; Wang, Y. Tracing the spatial variation and value change of ecosystem services in Yellow River Delta, China. Ecol. Indic. 2019, 96, 270-277. [CrossRef]

5. Gao, Y.; Wang, W.; Liu, X.; Zhang, L.; Dend, F.; Yang, C.; Sun, Q. Evaluation of carbon sequestration of forest ecosystem in Xiamen City. Res. Environ. Sci. 2019, 32, 2001-2007. [CrossRef]

6. Zhao, Q.; Wen, Z.; Chen, S.; Ding, S.; Zhang, M. Quantifying land use/land cover and landscape pattern changes and impacts on ecosystem services. Int. J. Environ. Res. Public Health 2019, 17, 126. [CrossRef] [PubMed]

7. Zhang, X.; He, S.; Yang, Y. Evaluation of wetland ecosystem services value of the yellow river delta. Environ. Monit. Assess. 2021, 193, 353. [CrossRef] [PubMed]

8. Ye, Y.; Zhang, J.; Wang, T.; Bai, H.; Wang, X.; Zhao, W. Changes in land-use and ecosystem service value in Guangdong Province, Southern China, from 1990 to 2018. Land 2021, 10, 426. [CrossRef]

9. Xie, G.; Cao, S.; Lu, C.; Xiao, Y.; Zhang, Y. Human's consumption of ecosystem services and ecological debt in China. J. Nat. Resour. 2010, 25, 43-51. [CrossRef]

10. Ouyang, Z.; Wang, X.; Miao, H. Preliminary study on the service function and eco economic value of terrestrial ecosystem in China. Acta Ecol. Sin. 1999, 19, 19-25. [CrossRef]

11. Zhao, J.; Xiao, H.; Wu, G. Comparison analysis on physical and value assessment methods for ecosystems services. Chin. J. Appl. Ecol. 2000, 11, 290-292. [CrossRef]

12. Groot, R.D.; Brander, L.; Ploeg, S.V.D.; Costanza, R.; Bernard, F.; Braat, L.; Christie, M.; Crossman, N.; Ghermandi, A.; Hein, L.; et al. Global estimates of the value of ecosystems and their services in monetary units. Ecosyst. Serv. 2012, 1, 5061. [CrossRef]

13. Costanza, R.; Groot, R.D.; Sutton, P.; Ploeg, S.V.D.; Anderson, S.J.; Kubiszewski, I.; Farber, S.; Turner, R.K. Changes in the global value of ecosystem services. Glob. Environ. Chang. 2014, 26, 152-158. [CrossRef]

14. Chen, Z.; Zhang, X. The value of ecosystem benefits in China. Chin. Sci. Bull. 2000, 45, 17-22. [CrossRef]

15. Xie, G.; Zhang, C.; Zhang, L.; Chen, W.; Li, S. Improvement of the evaluation method for ecosystem service value based on per unit area. J. Nat. Resour. 2015, 30, 1243-1254. [CrossRef]

16. Costanza, R.; d'Arge, R.; Groot, R.D.; Farber, S.; Grasso, M.; Hannon, B.; Limburg, K.; Naeem, S.; O’Neill, R.V.; Paruelo, J.; et al. The value of the world's ecosystem services and natural capital. Nature 1997, 387, 253-260. [CrossRef] 
17. Xie, G.; Lu, C.; Leng, Y.; Zheng, D.; Li, S. Ecological assets valuation of the Tibetan Plateau. J. Nat. Resour. 2003, 18, $189-196$. [CrossRef]

18. Li, H.; Li, Z.; Li, Z.; Yu, J.; Liu, B. Evaluation of ecosystem services: A case study in the middle reach of the Heihe River Basin, Northwest China. Phys. Chem. Earth 2015, 89-90, 40-45. [CrossRef]

19. Sutton, P.C.; Anderson, S.J.; Costanza, R.; Kubiszewski, I. The ecological economics of land degradation: Impacts on ecosystem service values. Ecol. Econ. 2016, 129, 182-192. [CrossRef]

20. Jiang, W.; Fu, B.; Lü, Y. Assessing impacts of land use/land cover conversion on changes in ecosystem services value on the Loess Plateau, China. Sustainability 2020, 12, 7128. [CrossRef]

21. Wang, Y.; Zhang, S.; Zhen, H.; Chang, X.; Shataer, R.; Li, Z. Spatiotemporal evolution characteristics in ecosystem service values based on land use/cover change in the Tarim River Basin, China. Sustainability 2020, 12, 7759. [CrossRef]

22. Yin, N.; Wang, S.; Liu, Y. Ecosystem service value assessment: Research progress and prospects. Chin. J. Ecol. 2021, 40, 233-244. [CrossRef]

23. Wu, C.; Ma, G.; Yang, W.; Zhou, Y.; Peng, F.; Wang, J.; Yu, F. Assessment of ecosystem service value and its differences in the Yellow River Basin and Yangtze River Basin. Sustainability 2021, 13, 3822. [CrossRef]

24. Su, K.; Wei, D.-Z.; Lin, W.-X. Evaluation of ecosystem services value and its implications for policy making in China-A case study of Fujian province. Ecol. Indic. 2020, 108, 105752. [CrossRef]

25. Ouyang, Z.; Zheng, H.; Xiao, Y.; Polasky, S.; Liu, J.; Xu, W.; Wang, Q.; Zhang, L.; Xiao, Y.; Rao, E.; et al. Improvements in ecosystem services from investments in natural capital. Science 2016, 352, 1455-1459. [CrossRef]

26. Yuan, Z.; Wan, R. A review on the methods of ecosystem service assessment. Ecol. Sci. 2019, 38, 210-219. [CrossRef]

27. Odum, H.-T.; Odum, E.-P. The energetic basis for valuation of ecosystem services. Ecosystems 2000, 3, 21-23. [CrossRef]

28. Sherrouse, B.-C.; Clement, J.-M.; Semmens, D.-J. A GIS application for assessing, mapping, and quantifying the social values of ecosystem services. Appl. Geogr. 2011, 31, 748-760. [CrossRef]

29. Sharps, K.; Masante, D.; Thomas, A.; Jackson, B.; Redhead, J.; May, L.; Prosser, H.; Cosby, B.; Emmett, B.; Jones, L. Comparing strengths and weaknesses of three ecosystem services modelling tools in a diverse UK river catchment. Sci. Total Environ. 2017, 584, 118-130. [CrossRef]

30. Villa, F.; Bagstad, K.-J.; Voigt, B.; Johnson, G.-W.; Portela, R.; Honzak, M.; Batker, D. A methodology for adaptable and robust ecosystem services assessment. PLoS ONE 2014, 9, e91001. [CrossRef]

31. Wang, X.; Liu, X.; Long, Y.; Liang, W.; Zhou, J.; Zhang, Y. Analysis of Soil retention service function in the North Area of Guangdong based on the InVEST model. In IOP Conference Series: Earth and Environmental Science, Proceedings of the Fourth International Workshop on Renewable Energy and Development, Sanya, China, 24-26 April 2020; IOP: Bristol, UK, 2020; Volume 510, p. 510. [CrossRef]

32. Gao, J.; Zuo, L. Revealing ecosystem services relationships and their driving factors for five basins of Beijing. J. Geogr. Sci. 2021, 31, 111-129. [CrossRef]

33. Hu, W.; Li, G.; Gao, Z.; Jia, G.; Wang, Z.; Li, Y. Assessment of the impact of the Poplar Ecological Retreat Project on water conservation in the Dongting Lake wetland region using the InVEST model. Sci. Total. Environ. 2020, 733, 139423. [CrossRef]

34. Zhang, X.; Zhou, J.; Li, M. Analysis on spatial and temporal changes of regional habitat quality based on the spatial pattern reconstruction of land use. Acta Geogr. Sin. 2020, 75, 160-178. [CrossRef]

35. Bai, Y.; Chen, Y.; Alatalod, J.; Yang, Z.; Jiang, B. Scale effects on the relationships between land characteristics and ecosystem services-A case study in Taihu Lake Basin, China. Sci. Total. Environ. 2020, 716, 137083. [CrossRef]

36. Aneseyee, A.B.; Elias, E.; Soromessa, T.; Feyisa, G.L. Land use/land cover change effect on soil erosion and sediment delivery in the Winike watershed, Omo Gibe Basin, Ethiopia. Sci. Total. Environ. 2020, 728, 138776. [CrossRef] [PubMed]

37. Geng, X.; Wang, X.; Yan, H.; Zhang, Q.; Jin, G. Land use/land cover change induced impacts on water supply service in the upper reach of Heihe River Basin. Sustainability 2014, 7, 366-383. [CrossRef]

38. Wang, X.; Dai, E.; Zhu, J. Spatial patterns of forest ecosystem services and influencing factors in the Ganjiang River Basin. J. Resour. Ecol. 2016, 7, 439-452. [CrossRef]

39. Fang, Z.; Bai, Y.; Jiang, B.; Alatalo, J.-M.; Liu, G.; Wang, H. Quantifying variations in ecosystem services in altitude-associated vegetation types in a tropical region of China. Sci. Total. Environ. 2020, 726, 138565. [CrossRef]

40. Aneseyee, A.B.; Noszczyk, T.; Soromessa, T.; Elias, E. The InVEST habitat quality model associated with land use/cover changes: A qualitative case study of the Winike Watershed in the Omo-Gibe Basin, Southwest Ethiopia. Remote Sens. 2020, $12,1103$. [CrossRef]

41. Zhang, J.; Ren, Z. Spatiotemporal pattern and terrain gradient effect of land use change in Qinling-Bashan mountains. Trans. Chin. Soc. Agric. Eng. 2016, 32, 250-257. [CrossRef]

42. Gong, W.; Yuan, L.; Fan, W. Analysis on land use pattern changes in Harbin based on terrain gradient. Trans. Chin. Soc. Agric. Eng. 2013, 29, 250-259. [CrossRef]

43. Chen, Y.; Li, J.; Xu, J. The impact of socio- economic factors on ecological service value in Hubei Province: A geographically weighted regression approach. Chin. Land Sci. 2015, 29, 89-96. [CrossRef]

44. Zeng, J.; Li, J.; Yao, X. Spatio-temporal dynamics of ecosystem service value in Wuhan Urban Agglomeration. Chin. Appl. Ecol. 2014, 25, 883-891. [CrossRef] 
45. Wang, Q.; Li, Y.; Liu, Y.; Hu, X. Analysis of spatial pattern of land use based on terrain gradient in karst trough valley area. Acta Ecol. Sin. 2019, 39, 7866-7880. [CrossRef]

46. Yang, B.; Wang, Z.; Yao, X.; Zhang, L. Terrain gradient effect and spatial structure characteristics of land use in mountain areas of northwestern Hubei province. Resour. Environ. Yangtze Basin 2019, 28, 313-321. [CrossRef]

47. Ma, S.; Qiao, Y.; Wang, L.; Zhang, J. Terrain gradient variations in ecosystem services of different vegetation types in mountainous regions: Vegetation resource conservation and sustainable development. For. Ecol. Manag. 2021, 482, 118856. [CrossRef]

48. Wang, L.; Ma, S.; Jiang, J.; Zhao, Y.; Zhang, J. Spatiotemporal variation in ecosystem services and their drivers among different landscape heterogeneity units and terrain gradients in the southern hill and mountain belt, China. Remote Sens. 2021, 13, 1375. [CrossRef]

49. Liu, W. Scientific understanding of the Belt and Road Initiative of China and related research themes. Prog. Geogr. 2015, 34, 538-544. [CrossRef]

50. Liu, H.; Yeerken, W.; Wang, C. Impacts of the Belt and Road Initiative on the spatial pattern of territory development in China. Prog. Geogr. 2015, 34, 545-553. [CrossRef]

51. Wang, Y.; Li, B.; Liu, J.; Feng, Q.; Liu, W.; Wang, X.; He, Y. Effects of cascade reservoir systems on the longitudinal distribution of sediment characteristics: A case study of the Heihe River Basin. Environ. Sci. Pollut. Res. 2021, 28, 1-13. [CrossRef]

52. Wang, B.; Zhao, J.; Hu, X. Spatial pattern analysis of ecosystem services based on InVEST in Heihe River Basin. Chin. J. Ecol. 2016, 35, 2783-2792. [CrossRef]

53. Ning, B.; He, Y.; He, X.; Li, Z. Research progress of water resources in Heihe River Basin. J. Desert Res. 2008, 28, $1180-1185$.

54. Tallis, H. Natural Capital: Theory and Practice of Mapping Ecosystem Services; Oxford University Press: Oxford, UK, 2011.

55. Lin, Y.-P.; Lin, W.-C.; Wang, Y.-C.; Wang, Y.-C.; Lien, W.-Y.; Huang, T.; Hsu, C.-C.; Schmeller, D.S.; Crossman, N.D. Systematically designating conservation areas for protecting habitat quality and multiple ecosystem services. Environ. Model Softw. 2017, 90, 126-146. [CrossRef]

56. Bao, Y.; Liu, K.; Li, T.; Hu, S. Effects of land use change on habitat based on InVEST model-taking Yellow River Wetland nature reserve in Shaanxi Province as an example. Arid Zone Res. 2015, 32, 622-629. [CrossRef]

57. Wang, Y.; Meng, J. Effects of land use change on ecosystem services in the middle reaches of the Heihe River Basin. Arid Zone Res. 2017, 34, 200-207. [CrossRef]

58. Zhou, W.; Liu, G.; Pan, J.; Feng, X. Distribution of available soil water capacity in China. J. Geogr. Sci. 2005, 15, 3-12. [CrossRef]

59. Zhao, Y. Evaluation of Watershed Ecosystem Service Function Based on Invest Model. Master's Thesis, Lanzhou University, Lanzhou, China, 2017. [CrossRef]

60. Gao, H.; Han, H.; Yu, H.; Han, M. Distribution characteristic of important ecosystem services in terrain gradient in Wujiang River Basin. Ecol. Sci. 2016, 35, 154-159. [CrossRef]

61. Xu, C.; Gong, J.; Li, Y.; Yan, L.; Gao, B. Spatial distribution characteristics of typical ecosystem services based on terrain gradients of Bailongjiang Watershed in Gansu. Acta Ecol. Sin. 2020, 40, 4291-4301. [CrossRef]

62. Jiang, S.; Meng, J.; Chen, Y. Analysis of hydrological effects of land use and landscape pattern in the middle reaches of Heihe River. Sci. Soil Water Conser. 2019, 17, 64-73. [CrossRef]

63. Li, Q.; Wang, L.; Yan, C.; Liu, H. Simulation of urban spatial expansion in oasis towns based on habitat quality: A case study of the middle reaches of Heihe River. Acta Ecol. Sin. 2020, 40, 2920-2931. [CrossRef]

64. Dun, Y.; Yang, C.; Yuan, X.; Yang, Y.; Xiao, F.; Liang, S.; Lu, X. Researches on watershed ecosystem services. Ecol. Econ. 2019, 35, 179-183.

65. Wang, P.; Li, Z.; Gao, W.; Yan, D.; Bai, J.; Li, K.; Wang, L. Glacier changes in the Heihe River Basin over the past 50 years in the context of climate change. Res. Sci. 2011, 33, 399-407. Available online: http://ir.casnw.net/handle/362004/8103 (accessed on 17 June 2021).

66. Wang, L.; Zhang, X. Effect of the recent climate change on water resource in Heihe River Basin. J. Arid Land Res. Environ. 2010, 24, 60-65. [CrossRef]

67. Zhang, K.; Wan, R.; Han, H.; Wang, X.; Si, J. Hydrological and water resources effects under climate change in Heihe River Basin. Res. Sci. 2007, 29, 77-83. [CrossRef]

68. Tian, F.; Lü, Y.; Fu, B.; Yang, Y.; Qiu, G.; Zang, C.; Zhang, L. Effects of ecological engineering on water balance under two different vegetation scenarios in the Qilian Mountain, northwestern China. J. Hydrol. 2016, 5, 324-335. [CrossRef]

69. Cheng, G.; Li, X.; Zhao, W.; Xu, Z.; Xiao, H. Integrated study of the water-ecosystem-economy in the Heihe River Basin. Natl. Sci. Rev. 2014, 1, 413-428. [CrossRef]

70. Xiao, S.; Xiao, H.; Mi, L.; Li, L.; Lu, Z.; Peng, X. Scientific evaluation on ecological effect of national comprehensive harnessing project of Heihe River Basin. Bull. Chin. Acad. Sci. 2017, 32, 45-54. [CrossRef]

71. Guo, K.; Xie, Y.; Wang, X.; Qiu, T. Characteristics of spatiotemporal distribution of temperature in the Heihe River Basin during the period 1960-2015. Res. Soil Water Conserv. 2020, 27, 253-260. [CrossRef] 
72. Su, L. Response of land use changes on ecological water diversion in midstream of the Heihe River Basin. In MATEC Web Conference, Proceedings of the First International Symposium on Water System Operations (ISWSO 2018), Beijing, China, 22-26 January 2018; EDP Science: Les Ulis, France, 2018; Volume 246, p. 246. [CrossRef]

73. Zhou, Y.; Li, X.; Yang, K.; Zhou, J. Assessing the impacts of an ecological water diversion project on water consumption through high-resolution estimations of actual evapotranspiration in the downstream regions of the Heihe River Basin, China. Agric. For. Meteorol. 2018, 249, 210-227. [CrossRef] 